\title{
An Empirical Examination of Matching Theories: The One Child Policy, Partner Choice and Matching Intensity in Urban China
}

\author{
Gordon Anderson* \\ Teng Wah Leo ${ }^{\dagger}$ \\ University of Toronto \\ St. Francis Xavier University
}

First Version: 1 January, 2007

This Version: 13 September, 2010

*Address: Department of Economics University of Toronto, 150 St. George Street, Toronto, Ontario, M5S 3G7, Canada. Email: anderson@chass.utoronto.ca

†Corresponding Author. Address: Department of Economics, St. Francis Xavier University, 1 West Street, Antigonish, Nova Scotia, B2G 2W5, Canada. Telephone: 1 (902) 867 5449. Fax: 1 (902) 867 3610. Email: tleo@stfx.ca

${ }^{\ddagger}$ We would like to thank Aloysius Siow, Loren Brandt, Lars Osberg, Kuan Xu, Christine Neill and Anindya Sen for their very helpful comments and suggestions, and seminar participants at CEPA at The University of Toronto, University of Waterloo, Dalhousie University, International University of Japan, the meetings of the Canadian Economics Association, and the Far Eastern \& South Asian meeting of the Econometric Society. 


\begin{abstract}
This paper introduces an index that facilitates the testing of differing matching theories based on the degree of overlap between a theoretically generated matching joint density and it's empirical counterpart. The index is asymptotically Normally distributed, consequently permitting inference. To demonstrate its use, the paper examined the effect the One Child Policy had on matching patterns in the marriage market in China. To distinguish between confounding policies of the period, a static general equilibrium model is introduced. It predicts that constraining marital output in the child quantity dimension may raise the marginal benefit of positive assortative matching and investment in child quality, thereby increasing the intensity with which they are pursued and concomitantly reducing the marriage rate. Upon verifying that the policy was binding via a Poisson model, using the matching index, significant support for increases in positive assortative matching and reductions in negative assortative matching was found.
\end{abstract}

JEL Code: J12, J13

Key Words: Overlap Measure; Matching; Marriage; Education 


\section{Introduction}

Becker (1973) showed that positive assortative matching will be the outcome of a static transferable utility marriage market model when the marriage output function is complementary/supermodular in the qualities of the spouses 11 Since then substantial theoretical work has sought to extend it and qualify its prediction within a stati ${ }^{2}$ or dynamid ${ }^{3}$ setup. While empirical work has focused on the the estimation of marriage models 4 and testing of the positive assortative outcome generated by Becker's (1973) mode $\rfloor^{5}$, it is to the latter literature that this paper builds and adds on to.

Insofar as the testing of positive assortative matching pertains to the examination of the joint density generated by spousal qualities within a marriage market, the question of testing for positive assortative matching in general has a close cousin in the empirical mobility literature that has focused on examining the transition matrix 6 and stochastic dominance measures?. Siow (2009) comes closest in spirit to this paper, where he devised a measure to test the positive assortative matching prediction and to identify it as a consequence of supermodularity, as opposed to pure preference by the constituents of the marriage market for potential spouses that are similar in attribute. The approach developed is based on stochastic ordering in statistics (Shaked and Shanthikumar 2007) which relies on investigating the total positivity, or more precisely the determinant, of a joint density matrix under consideration.

The first objective of this paper is to introduce an alternative method of testing matching theories. The approach draws from Anderson et al. (2010) and Anderson, Linton and Whang (2009), and relies on quantifying the proximity between an observed joint den-

\footnotetext{
${ }^{1}$ This was summarized in Becker (1993). Siow (2009) provides significant insight into the implications of the theory.

${ }^{2}$ See for example Burdett and Coles (1997), Damiano, Li and Suen (2005), Iyigun and Walsh (2007), Legros and Newman (2002), Legros and Newman (2007), Lundberg and Pollak (2003) and Peters and Siow (2002)

${ }^{3}$ See for example Atakan (2006) and Shimer and Smith (2000)

${ }^{4}$ See Bergstrom and Lam (1994), Choo and Siow (2006a), Choo and Siow (2006b), Dagsvik (2000) and Wong (2003).

${ }^{5}$ Abowd, Kramarz and Margolis (1999), Fernandez, Guner and Knowles (2005), Galichon and Selanie (2009), Lise, Meghir and Robin (2008), Liu and Lu (2006), de Melo (2008), Mendes, Berg and Lindeboom (2007), Siow (2009) and Suen and Lui (1999).

${ }^{6}$ See Anderson, Ge and Leo (2010), Anderson et al. (2010), Dardanoni (1993), Maasoumi (1996), Quah (1996), Shorrocks (1976), and Shorrocks (1978)

${ }^{7}$ See Anderson (1996), Atkinson (1970), Bourguignon and Fields (1997), Davidson and Duclos (2000)
} 
sity to a hypothesized matching density, the Overlap Measure. In essence, the measure quantifies the degree of similarity between the two densities over the entire support as an index defined on the interval $[0,1]$, reflecting the degree of overlap between the empirical and theoretical joint densities. As the empirical density tends towards mimicking a hypothesized density, the overlap measure tends toward one, and zero otherwise. In other words, the main advantage of this measure is that it quantifies how well a proposed model fits the observed data. A second significant advantage of this measure, as will be shown, is that it is asymptotically Normally distributed, thereby facilitating inferences regarding alternative hypotheses, in other words whether one is significantly better than the other. A final advantage of the measure is that it does not require the joint density matrix generated by the theory or marriage market to be square.

The second objective is to demonstrate how the testing technique can be employed in examining the consequences of the introduction of the Chinese One Child Policy (OCP) for education based marital matching. This policy, implemented most stringently in Urban China in 1979, is one of the most far reaching population control policies in recent history and has been the subject of much study. However, to the authors' knowledge, its impact on marital partner choice has not previously been a matter for consideration. By comparing the overlap measure against both perfect positive and negative assortative matching over three urban cohorts within six provinces that straddled the implementation of the OCP, the paper provides an ordered matching index through which changes in matching patterns and intensity can be tracked. Unfortunately changing trends in familial choices that predate the OCP together with concurrent implementation of the Economic Reforms package could confound the analysis. Thus the final objective is to provide a model that merges the matching and familial choice models from Becker (1973) and Becker (1993), which serves to identify the effects of these different influences. The model predicts that a policy that limits family size would lead to an increase in postive assortative and decrease in negative assortative matching, and consequently a decrease in match rate. As a preamble to the empirical application, we found significant support for the predictions.

In the following, section 2 introduces the Overlap Measure and it's applicability in testing matching hypotheses. Section 3 provides the historical context of the OCP, and trends in familial choice during those decades, which motivates the theoretical model therein. Section 4 provides a data summary and establishes the sense in which the number of children in the family have been effectively rationed. Hypotheses about partner 
choice decisions are examined empirically in section 5 , followed finally by a discussion and conclusion.

\section{Method of Testing Matching Hypotheses}

\subsection{The Overlap Measure}

For simplicity, consider a marriage market where individuals are matched on a single attribute $t_{g}^{k}$ where $g \in\{h, w\}$ ( $h$ denotes a male, and $w$ denotes a female) and $k=$ $\{1,2, \ldots, n\}$, such that $t_{g}^{1}<t_{g}^{2}<\ldots<t_{g}^{n}$, in other words the attribute has $n$ ordered realizations. Let $\mathbf{J}_{e}$ be the empirical/observed joint density matrix of matches in the marriage market with $j_{i, k}^{e} i, k=\{1,2, \ldots, n\}$ being it's elements. Similarly, the theoretically generated joint density matrix is $\mathbf{J}_{t}$ with $j_{i, k}^{t}$ being it's typical element. Then the Overlap Measure proposed is of the form,

$$
O V_{t}=\sum_{i=1}^{n} \sum_{k=1}^{n} \min \left\{j_{i, k}^{t}, j_{i, k}^{e}\right\}
$$

Although this measure has a continuous counterpart (Anderson et al. 2009), because attributes or indices considered in the matching literature are typically discrete in nature, the Overlap Measure as proposed by Anderson et al. (2010) is the natural candidate measure. At one extreme when the two densities are a perfect match $O V_{t}=1$, while at the other when the two densities have no common support then $O V_{t}=0$, consequently the support of $O V_{t}$ is $[0,1]$.

To provide a better grasp of the idea, consider two univariate densities from two differing populations. Intuitively the Overlap Measure quantifies the degree of overlap as depicted in figure 1 in two dimensions. As the degree of overlap of the densities tends to one, the greater is the explanatory power of the matching theory.

An often overlooked detail is that there is no a priori reason why the support of the attributes on both sides of the market should be the same. In other words, the joint density of matches need not generate a square matrix. Whereas most other measures employed thus far require the joint density matrix to be square, the overlap measure is still viable when it is not. The measure is also amenable to use in multivariate domains, although to our knowledge, there has been no attempt in generating an equilibrium matching array. 
Figure 1: Overlap Between Densities $f$ and $g, O V$

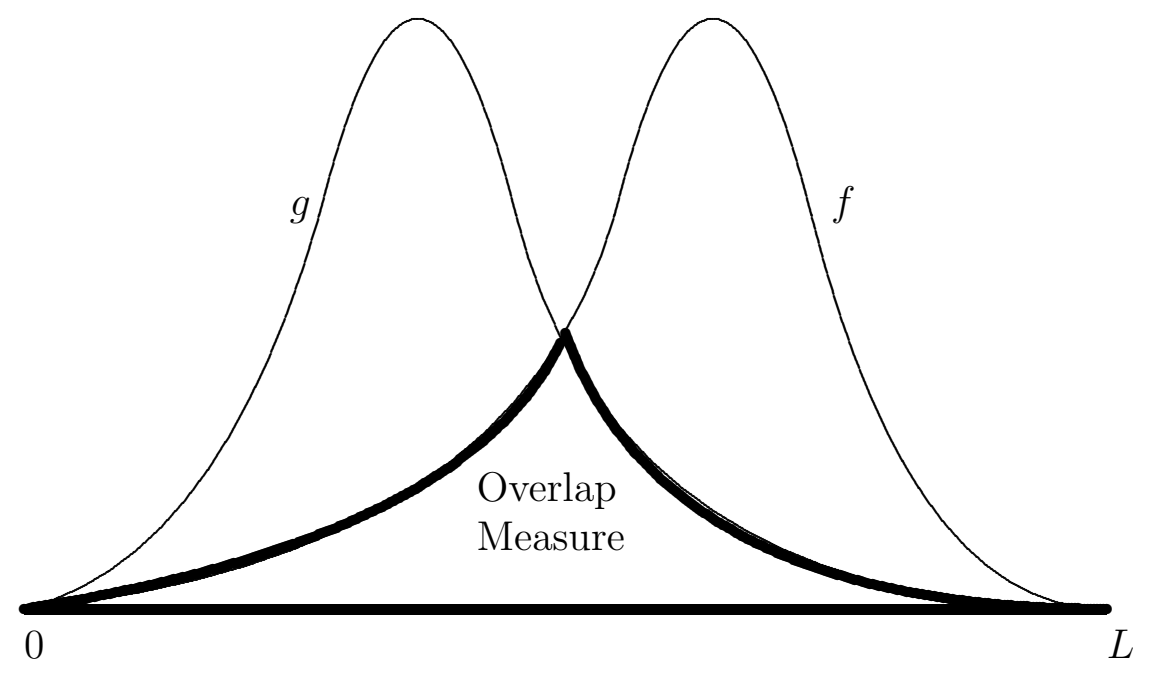

Finally, the Overlap Measure is asymptotically Normally distributed, which consequently allows for inference (A short explanation is provided in appendix A.2). For instance, in considering two matching models, the researcher could determine if one yields a significantly better fit. Further, as will be discussed in more detail below, with a suitably indexed hypothetical joint density matrix (corresponding to perfect positive/negative assortative matching for example), the researcher could determine if the marriage market is trending in a particular manner. In other words this presents a reduced form method of determining if there is increased or decreased intensity in a particular type of matching pattern.

\subsection{Natural Ordering of the Matching Matrix}

Matching intensity can be ordered in a reduced form fashion by relying on what can be achieved under perfectly positive/negative assortative matching. This method of ordering allows the researcher to examine how the intensity of matches within a marriage market has changed across the population and time.

For simplicity, suppose the attribute space of both husbands and wives are partitioned into five mutually exclusive realizations such that $t_{g} \in\left\{t_{g}^{1}, t_{g}^{2}, \ldots, t_{g}^{5}\right\}$ where $g \in\{h, w\}$ and $t_{g}^{1}<t_{g}^{2}<\ldots<t_{g}^{5}$. If the partitions are matched such that $\operatorname{Pr}\left(t_{h}=t_{h}^{k}\right)=\operatorname{Pr}\left(t_{w}=t_{w}^{k}\right)$ for all $k \in\{1,2, \ldots, 5\}$, letting the row index denote the male type partitions and the 
columns denote the female type partitions, then the joint density under a null of perfect assortative matching 8 is of the form,

$$
\mathbf{J}_{p}=\left[\begin{array}{cccc}
\operatorname{Pr}\left(t_{i}=t_{i}^{1}\right) & 0 & \cdots & 0 \\
0 & \operatorname{Pr}\left(t_{i}=t_{i}^{2}\right) & \cdots & 0 \\
\vdots & \vdots & \ddots & \vdots \\
0 & 0 & \ldots & \operatorname{Pr}\left(t_{i}=t_{i}^{5}\right)
\end{array}\right]
$$

Under this scenario of a perfectly matched marriage market, this matrix would be the "theoretical" joint density matrix against which the empirical density matrix is compared. Then the closer the empirical matrix $\mathbf{J}_{e}$ is to $\mathbf{J}_{p}$, the more positively assortatively matched would the sample be.

Sometimes it is not possible to partition the support of types as above, for example when both sides of the marriage market are not matched in terms of the attribute, the perfectly positive assortative matching matrix would have it's elements spill onto the offdiagonal cells. Suppose that the partition is not matched such that $\sum_{k=1}^{m} \operatorname{Pr}\left(t_{h}=t_{h}^{k}\right) \leq$ $\sum_{k=1}^{m} \operatorname{Pr}\left(t_{w}=t_{w}^{k}\right)$ for $m \in\{1,2, . ., 5\}$, that is men stochastically dominate women in the realizations. Then the joint density matrix under perfect positive assortative matching, assuming offers are made by men and that higher type men can always outbid lower type men for a potential match, would be of the form:

$$
\mathbf{J}_{p}=\left[\begin{array}{ccccc}
\operatorname{Pr}\left(t_{h}=t_{h}^{1}\right) & 0 & \ldots & 0 & 0 \\
\operatorname{Pr}\left(t_{h} \geq t_{h}^{2}\right)-\operatorname{Pr}\left(t_{w} \geq t_{w}^{2}\right) & \operatorname{Pr}\left(t_{w} \geq t_{w}^{2}\right)-\operatorname{Pr}\left(t_{h} \geq t_{h}^{3}\right) & \ldots & 0 & 0 \\
0 & \operatorname{Pr}\left(t_{h} \geq t_{h}^{3}\right)-\operatorname{Pr}\left(t_{w} \geq t_{w}^{3}\right) & \ldots & 0 & 0 \\
\vdots & \vdots & \ddots & \vdots & \vdots \\
0 & 0 & \ldots & \operatorname{Pr}\left(t_{h}=t_{h}^{5}\right)-\operatorname{Pr}\left(t_{w}=t_{w}^{5}\right) & \operatorname{Pr}\left(t_{w}=t_{w}^{5}\right)
\end{array}\right]
$$

\footnotetext{
marginal density case it follows that,

$$
\mathbf{J}_{n}=\left[\begin{array}{cccc}
0 & \cdots & 0 & \operatorname{Pr}\left(t_{i}=t_{i}^{1}\right) \\
0 & \cdots & \operatorname{Pr}\left(t_{i}=t_{i}^{2}\right) & 0 \\
\vdots & \ddots & \vdots & \vdots \\
\operatorname{Pr}\left(t_{i}=t_{i}^{5}\right) & \cdots & 0 & 0
\end{array}\right]
$$
}

${ }^{8}$ Under the null hypothesis of negative assortative matching, $\mathbf{J}_{n}$ is a counter-diagonal matrix, with the highest type individuals matching with the lowest type from the other gender. In the perfectly matched 
Estimates of such a matrix can be constructed from the empirical marginal distributions of men's and women's attribute realizations. Although only results using the above matrix are reported in the following application using a single spousal attribute/quality, there are other methods of arriving at the positive and negative assortative matching matrix which were examined as well in the application that follows, namely when the offers are made by women to men (For a detailed discussion of the difference this generates, see Roth and Sotomayor (1990), particularly theorem 2.13 due to Knuth (1976)) and when the preference for own type is strongest (that is matching clears the diagonal first) 9 . One of the advantages of the Overlap Measure is it's power, which allows it to discern between joint density matrices generated by differing matching theories, because the measure places equal weight on all cells of the matrix.

\section{The Effect of the One Child Policy on Matching in Urban China}

Introduced in 1979, the OCP represented a considerable intervention in the household choice process through it's enforcement. The primary rationale for the policy was to avert the foreseen strain on the limited economic and agricultural resources as the economy sought economic growth. The policy was implemented and enforced through fines and various other forms of coercion. Such an intervention could conceivably have changed the nature of both existing and anticipated marriage arrangements, and can be expected to have influenced family formation decisions in numerous dimensions, for instance in the choice of partner, the family size and investments in children. As such it appears to provide a natural pseudo experiment, ceteris paribus, through which the nature of family formation and familial choices could be examined. However, not all else is equal and some context for the policy is appropriate.

There is a sense in which the desired outcome of the policy was not at odds with the background against which it was introduced. Fertility (number of live births per married woman aged 20-44) was already in considerable decline prior to the OCP, having fallen to 2.2 in 1980 from 6.4 in 1965. This phenomenon could be rationalized as a

\footnotetext{
${ }^{9}$ These results are available from the authors upon request, although they did not produce as close a fit to the empirical joint density as equation (3) suggesting that the prevailing matching mechanism is the one underlying equation (3).
} 
result of urbanization ${ }^{10}$, which diminishes preference for larger families (Therborn 2004), consequently implying that the policy may not be binding for some of the urban populace, for which there is some evidence in terms of completed families with one or fewer children pre-policy. Consequently, whether the OCP was binding in our sample will have to be verified empirically first.

On the other hand, within the premise of a binding policy ${ }^{11}$, changes in the apparent preference for sons in China have to be contended with (The usual boy/girl sex ratios at birth are around 104/100, while China's in 1995 for example was 117/100 (Peng and Guo 2000)). These preferences are apparently founded upon a tradition of patrilocal residence of married sons who, as opposed to daughters, provide considerable old age security benefits for their parents (See Therborn (2004) who suggested that expression of these preferences has been facilitated by the development and availability of fetus gender detection and selective abortion techniques ${ }^{12}$.). Such preferences however may well be more strongly held in rural as opposed to urban locales. The primary difficulty this presents is that it reduces the individual's ability to achieve their desired matches, and consequently prevent the detection of possible effects on matching due to the OCP.

Finally, the OCP was introduced in tandem with the Economic Reforms of 1979 which precipitated a well documented increase in the incomes of the populace. Should this increase have the propensity to bring about similar changes in family structure, it would not be possible to distinguish the effects of these two policies. Essentially this presents an identification problem which, as will become apparent, is to some degree resolved by the theoretical model discussed below, since it predicts opposing effects for economic growth and the OCP with respect to spousal choice decisions.

\subsection{Model of Spousal Matching Intensity and Familial Choice}

The substitutability between family size and the quality of their offspring has been examined by the demographer Caldwell (1982) who argued that fertility was high when children are an asset to their parents, and low when they become a liability. Becker (1993) for-

\footnotetext{
${ }^{10}$ In $19497.3 \%$ of the population was urbanized, however by 1990 20.1\% was urbanized (Anderson and Ge 2005)

${ }^{11}$ Within the rural context, Zhang (2002) found that the OCP did present a binding constraint.

${ }^{12}$ Doherty, Norton and Veney (2001) found significant reduction in usage of pre-natal and obstetrics care among women with the implementation of the OCP that cannot be explained by price changes. Their result may suggest that the intensity with which male child preference is sort has fallen.
} 
malized this idea in his model where both number of and quality of children feature as part of the household decision process, and can be used to rationalize the effect of urbanization and the preference for sons at birth. An important feature of Becker's analysis is that quantity and quality choices are simultaneous, with each influencing the other to an extent ${ }^{13}$. He demonstrated that while quantity and quality are likely to be substitutes, they cannot be close substitutes (because the budget constraint between quantity and quality is convex, equilibrium would not exist if the indifference curve between quantity and quality were in some sense "less" convex).

On the theoretical exposition of matching within the context of the family, Becker's (1973) theory of positive assortative matching showed that positive assortative spousal matching will be the consequence when the marriage output function or the gains to marriage are complementary/supermodular in the qualities of the individuals entering into the marriage. The task then is to synthesize the separate concerns of marital matching and familial choices within a marriage to examine their behavior when they interacted with each other.

We now provide a static general equilibrium model of marital matching that merges the dual concerns, where choice of a spousal match is dependent on the individual's measurable continuously distributed attribute or quality as well as the consequent choices in child quality and quantity. This approach permits the examination of how a binding constraint on child quantity (Neary and Roberts (1980); Deaton (1981)) affects spousal choice endogenously. Intuitively, if individuals on both sides of the marriage market are forward looking, the policy will affect the choice of partner decision by rendering the owner of childrearing attributes less of a comparative advantage relative to someone with greater income generating attributes all other things equal.

\subsubsection{Model Setup}

Consider a model where an individual lives for 2 periods, one as a child, and the other as an adult. At the beginning of the adult period, agents choose to marry or remain single

\footnotetext{
${ }^{13}$ Family formation has most frequently been discussed as an adjunct to the study of female labour supply. The issue being whether fertility should or should not be an argument in the labour supply equation, which in turn hinges on the nature of the planning horizon. One practice in modelling female labour supply is to assume that lifetime fertility decisions are made early in life, "at marriage is the most popular choice"(Browning 1992). The alternative is to assume a simultaneous model where the agent attempts to have more children while making her labour supply decision.
} 
(there is no divorce in this model) ${ }^{14}$. The rate at which an adult meets someone of the opposite gender is random. Marriage is dependent on the attribute/quality realization of the man and woman, and utility is assumed to be transferable. Let the agent's type $t_{g}, g \in\{h, w\}$, be continuous on a support $[\underline{t}, \bar{t}], \underline{t}, \bar{t} \in \mathbb{R}$, and distributed with density $f($.$) and distribution F($.$) for both male and female. Upon marriage, they will choose$ the number of children to have and the amount of investment in each child. The aspect of utility derived from children is described by a function $q($.$) dependent on the type of$ the parents, the number of children $n$, and the amount of investment per child $k$, that is $q \equiv q\left(t_{h}, t_{w}, k, n\right)$, such that $q \mapsto\{0\}+\mathbb{R}_{+}$is increasing and concave in all it's inputs. The other aspect of a married individual's utility is derived from personal consumption $c_{g}$, $g \in\{h, w\}$. Finally, the utility function is multiplicatively separable in the utility derived from the children and that from own consumption, $u_{h}=q\left(t_{w}, n, k \mid t_{h}\right) c_{h}$. If instead the individual chooses to remain single, utility will only be derived from personal consumption which in turn is dependent on his/her own type, $s_{g}=\max _{c_{g}} c_{g}, g \in\{h, w\}$.

The income realization of the family or individual is assumed to be dependent on the type of match and the individual's attribute respectively. Specifically, family income is assumed to be $y x\left(t_{h}, t_{w}\right)$, and income for a single individual to be $y v\left(t_{g}\right), g \in\{h, w\}$, where $y$ is the average income within the economy, $x:\left(t_{h}, t_{w}\right) \mapsto\{0\}+\mathbb{R}_{+}$and $v: t_{g} \mapsto\{0\}+\mathbb{R}_{+}$. This setup thus abstracts from redistributive concerns arising from any policy, which is beyond the scope of this paper. Further, this formulation of income together with the range of $q$ ensures that for some matches and individual attributes, the choice of remaining single will be made. That is the set of single individuals by attribute realization is nonempty.

The following functional assumptions are also made,

Assumption 1 : Investment in children, $k$, and the choice of the number of children, $n$, are substitutes in the function $q($.$) . That is q_{k, n}\left(t_{w}, n, k \mid t_{h}\right) \leq 0$.

Assumption $2: u_{t_{g}} \geq 0, u_{t_{g}, t_{g}} \leq 0$, for $t_{g} \in[\underline{t}, \bar{t}], g \in\{h, w\}$.

\footnotetext{
${ }^{14}$ The focus is on gains from marriage and how it affects matching and child investment decisions, thus without loss of generality we solve the problem from the perspective of men, apportioning all the rents from marriage to them. The imposition of other sharing rules will not affect the essence of the results presented below.
} 


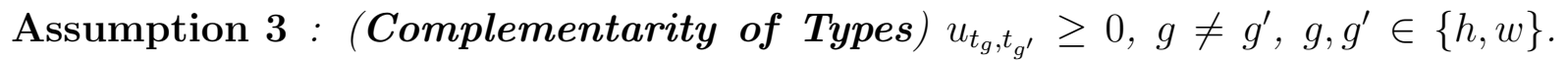
Further, let $t^{*}=\arg \max _{t_{w} \in[\underline{t}]} u\left(t_{w}, n, k \mid t_{h}\right) \Leftrightarrow t^{*}=t_{h}=t_{w}$, for $t_{h}, t_{w} \in\{\underline{t}, \bar{t}\}$.

Assumption 4 : (Convex in Types When Single): $v_{t_{g}} \geq 0, v_{t_{g}, t_{g}} \geq 0, g \in\{h, w\}$. Assumption 5: (Single Crossing with respect to Average Income): $\frac{\partial u_{h}}{\partial y}, \frac{\partial s_{h}}{\partial y}>$ $0, u_{h}(y=0) \leq s_{h}(y=0)$, and that $\frac{\partial u_{h}}{\partial y} \geq \frac{\partial s_{h}}{\partial y}$.

Assumption 1 creates the tradeoff between the choice of investment per child, and the number of children in a family. Assumption 2 ensures that $u_{g}(). g \in\{h, w\}$ is well behaved on the support of the agent's attribute realization. Assumption 3 says that given an agent's attribute, they would prefer to be matched with someone of the same realization or better. Together with assumption 4, this ensures that agents would always prefer to match with someone closer to their own type, since the concavity of $u_{g}(). g \in\{h, w\}$ in own attribute realization and that of the spouse, and the convexity of $v($.$) in own$ realization ensures that gross marital output attains a maxima, for agents of a sufficiently low type, on the support. The reason assumptions 2 and 3 are not placed on the child quality function $q($.$) is that otherwise the model would have to contend with qualifying the$ conditions under which complementarity/supermodularity would exist for the marriage output function which is beyond the scope of this mode ${ }^{15{ }^{16}}$.

Assumption 5 pertains to the effect of income on preferences in the marriage and single state. It ensures that utility gained from marriage increases at a faster rate with respect to income than in the single state, so that once an individual finds marriage desirable at his current income, increases in it will not reduce his desire to be married. Put another way, consider two individuals who are completely the same in attribute with the poorer individual being married "happily", the assumption assures that the one with higher income would not rather be single. Or put colloquially "money cannot change an individual" in this model. Technically, it ensures that the utility, with respect to income, from marriage and being single can intersect at most once.

Abstracting from intra-household bargaining and focusing on the total value of marital output, without loss of generality the solution to the individual's problem will now be solved from the perspective of the man choosing a prospective wife.

\footnotetext{
${ }^{15}$ An example of a function that would meet these assumptions is when $q($.$) and x($.$) are quadratic$ functions with respect to $\left(t_{h}-t_{w}\right)$ on $t_{h}, t_{w} \in[0,1]$.

${ }^{16}$ We suspect a model with search costs that fall as agent types rises may generate similar results we present below.
} 


\subsubsection{The Effect of OCP on Child Quality \& Assortative Matching Intensity}

If an individual of type $t_{g} g \in\{h, w\}$, chooses to remain single, he solves,

$$
\max _{c_{g}} c_{g}
$$

subject to

$$
y v\left(t_{g}\right) \geq c_{g}
$$

where $y$ is the average income, and $v: t_{g} \mapsto 0+\mathbb{R}_{+}, g \in\{h, w\}$. The optimized utility of this single individual is,

$$
\widehat{s}_{g} \equiv \widehat{s}\left(t_{g}\right)=c_{g}^{*}=y v\left(t_{g}\right)
$$

which implies that his income is a proportion of the average income, dependent on his attribute realization.

On the other hand, should the individual find a suitable match, he maximizes his utility subject to his budget and participation constraints:

$$
\max _{n, c_{h}, c_{w}, k} q\left(t_{w}, n, k \mid t_{h}\right) c_{h}
$$

subject to

$$
\begin{aligned}
c_{h}+c_{w}+n k & \leq y x\left(t_{h}, t_{w}\right) \\
q\left(t_{w}, n, k \mid t_{h}\right) c_{w} & \geq y v\left(t_{w}\right)
\end{aligned}
$$

where $c_{h}$, and $c_{w}$ are the consumption choices, and $t_{h}$ and $t_{w}$ are the attribute realization for the husband and wife respectively. By the usual non-satiation argument, the budget constraint holds with equality, and since the husband can always make himself better off by just meeting the participation constraint, it holds with equality as well. Therefore,

$$
c_{h}=y x\left(t_{h}, t_{w}\right)-n k-\frac{y v\left(t_{w}\right)}{q\left(t_{w}, n, k \mid t_{h}\right)}
$$

and he solves,

$$
\max _{n, k} q\left(t_{w}, n, k \mid t_{h}\right)\left(y x\left(t_{h}, t_{w}\right)-n k\right)-y v\left(t_{w}\right)
$$

The first order conditions are thus,

$$
\begin{aligned}
& q_{n}\left(t_{w}, n^{*}, k^{*} \mid t_{h}\right)\left(y x\left(t_{h}, t_{w}\right)-n^{*} k^{*}\right)=q\left(t_{w}, n^{*}, k^{*} \mid t_{h}\right) k^{*} \\
& q_{k}\left(t_{w}, n^{*}, k^{*} \mid t_{h}\right)\left(y x\left(t_{h}, t_{w}\right)-n^{*} k^{*}\right)=q\left(t_{w}, n^{*}, k^{*} \mid t_{h}\right) n^{*}
\end{aligned}
$$


where $k^{*}$ and $n^{*}$ are the optimal values for investment per child, and number of children respectively. In equilibrium, the following condition will hold,

$$
\frac{q_{n}\left(t_{w}, n^{*}, k^{*} \mid t_{h}\right)}{k^{*}}=\frac{q_{k}\left(t_{w}, n^{*}, k^{*} \mid t_{h}\right)}{n^{*}}
$$

However, under a situation where $n$ is no longer a choice variable, only (7) would prevail, hence the effect of changes in $n$ on the optimal choice of $k$ can be examined as if $n$ is a parameter. Let $\widetilde{n}$ denote the exogenously constrained number of children, and let the respective optimal choice of investment for each child be $k^{\prime}$ in that scenario.

Since the OCP coincided with the Chinese Economic Reforms, which precipitated considerable economic growth, should the impact of economic growth on familial choices yield similar outcomes, it would not be possible to identify the separate policy effects. The following four propositions relate to how the OCP and economic growth might have affected spousal and family size choices (proofs are supplied in appendix A.1).

First, let $\widehat{u}_{h}=\max _{n, k} q\left(t_{w}, n, k \mid t_{h}\right)\left(y x\left(t_{h}, t_{w}\right)-n k\right)-y v\left(t_{w}\right)$ and $\widehat{s}_{h}=y v\left(t_{h}\right)$, then a type $t_{h}$ man's second period utility is,

$$
U_{h}=\max \left\{\widehat{u}_{h}, \widehat{s}_{h}\right\}
$$

The reservation type of his potential spouse is determined by

$$
\begin{aligned}
\widehat{u}_{h} & =\widehat{s}_{h} \\
\Rightarrow q\left(\underline{t_{w}^{R}}, \underline{n}, \underline{k} \mid t_{h}\right)\left(y x\left(t_{h}, \underline{t_{w}^{R}}\right)-\underline{n k}\right)-y v\left(\underline{t_{w}^{R}}\right) & =y v\left(t_{h}\right)
\end{aligned}
$$

where $\underline{n}$ and $\underline{k}$ are the optimal values for a match between a man of type $t_{h}$ and woman of type $\underline{t_{w}^{R}}$. Letting $\underline{t_{w}^{R}} \equiv \underline{t_{w}^{R}}\left(t_{h}\right)$, from figure 2 it may be observed that 10 determines only the lower bound of the reservation at point A. For spousal types below $t_{w}^{R}$, although he may be collecting all the rents, he obtains no net benefit from marriage. It is only above $\underline{t_{w}^{R}}$ that marital utility would exceed his utility from remaining single.

Men of sufficiently low attribute realization may have an upper bound on the type of his spouse, $\overline{t_{w}^{R}}$, beyond which the marital gains from the match may not be sufficient for him to compensate her. She obtains at least $\widehat{s}\left(\overline{t_{w}^{R}}\right) \equiv \widehat{s}_{w}$, the utility she would get from remaining single. This upper threshold is determined by

$$
q\left(\overline{t_{w}^{R}}, \bar{n}, \bar{k} \mid t_{h}\right)\left(y x\left(t_{h}, \overline{t_{w}^{R}}\right)-\bar{n} \bar{k}\right)-\widehat{s}\left(\overline{t_{w}^{R}}\right)=\widehat{s}_{h}=y v\left(t_{h}\right)
$$

The upper bound is point B in figure 2. The type of woman that would present as the optimal spousal type occurs when the marginal gain in gross marital utility from choosing 
a higher type spouse equates with the marginal increase in cost he would have to transfer to meet her participation constraint. This is where the slope of the gross utility and $\widehat{s}_{w}=y v\left(t_{w}\right)$ equates, and coincides at the man's own attribute realization. Beyond this optimal realization, his own marital gains start decreasing, and eventually falls below his upper reservation value for marriage. Further, although by construction the man's marriage output is optimized when his spouse has the same attribute realization, there will still be matches "off the diagonal" given random matching.

Figure 2: Reservation Values given Type

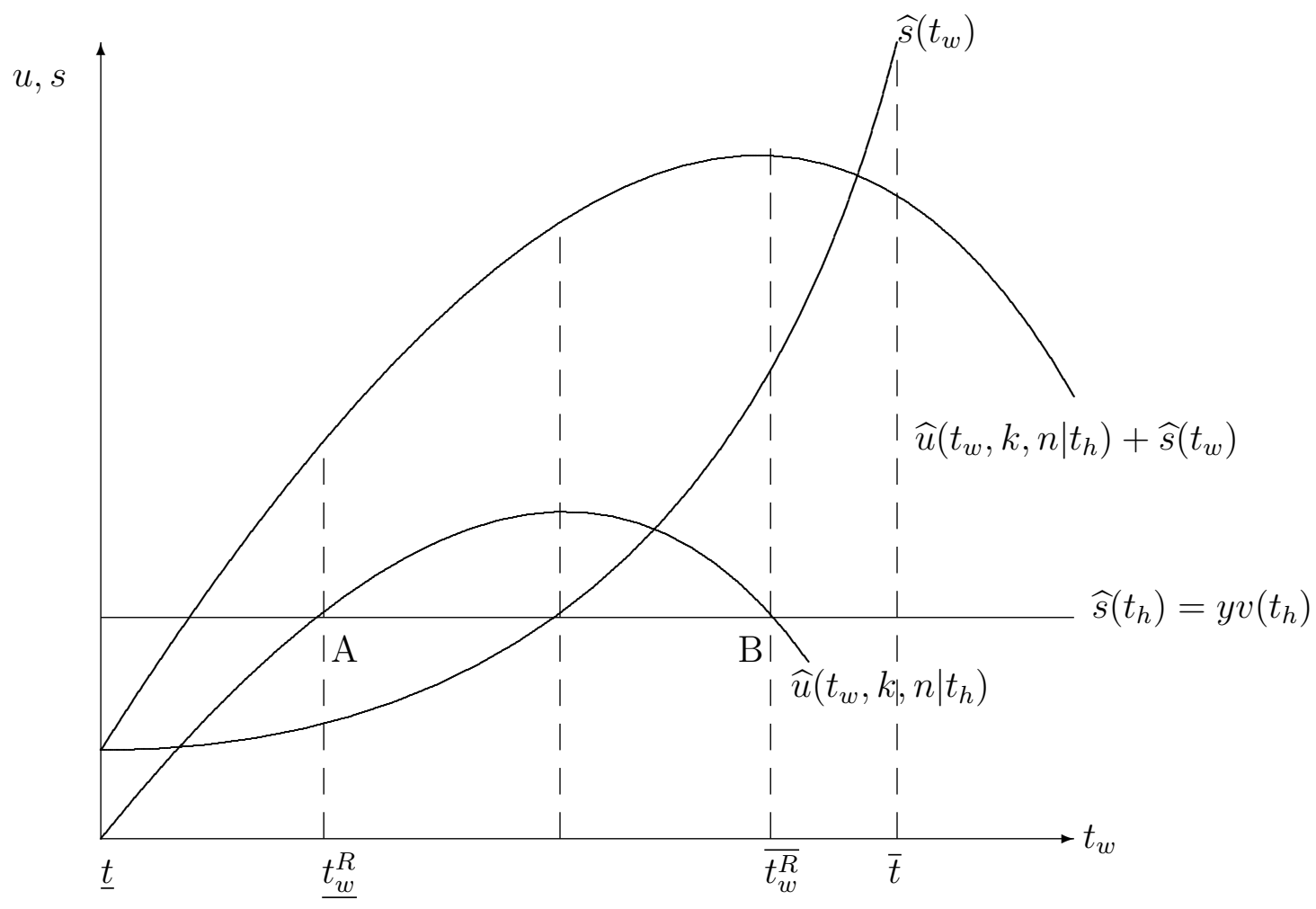

Intuitively, given that quantity and quality of children are substitutable, a binding policy that impinges on a family's choice in one dimension should yield an increase in the remaining dimension, which is stated in the following proposition.

Proposition 1 : An exogenously enforced reduction in the number of children raises equilibrium investment in children.

Yet the success of the Economic Reform of 1979, which raised the incomes and consequently the quality of lives among the Chinese populace, should similarly raise familial 
investments in children, assuming children are normal goods. That the reform came at the same time as the OCP would accentuate the increase in investments (holding the nominal cost of investments constant), and consequently child quality.

Proposition 2 : An exogenous increase in income would increase the number of children born into the family and/or the level of investment per child.

Propositions 1 and 2 imply that the OCP and Economic Reform of 1979 would have reinforced each other, preventing identification of the cause of changes in investment in children if any ${ }^{17}$.

However the manner in which either policy could have effected spousal choices can also be examined. Intuitively, spousal choice remains a venue through which individuals could adjust to the enactment of the OCP to maintain the gains to marriage. Child outcomes are dependent on both ongoing investment as well as genetically endowed qualities from their parents. Thus the exogenous rationing of child quantity could have also accentuated the importance of good spousal match, assuming positive assortative matching is the norm. Note the existence of positive assortative matching is not disputed, rather the intensity of positive assortative matching may have been altered.

Proposition 3 : When the number of children is fixed below the optimal choice that a married couple would have chosen given their attribute realization, then:

1. for all men, the lower bound on the reservation type of a prospective spouse would rise, while the upper bound would fall, and

2. agents who choose to marry would exhibit increased assortative matching.

To illustrate proposition 3 , let there be two broad groups of men, those who benefit from marriage, but who would never be able to attract high type spouses relative to their own type (M), and those who are coveted by all spousal types (H). Figure 3 shows that with a binding family size policy, matches with lower type women yield lower marital output in the post policy regime, consequently shifting the lower bound on the reservation type closer to one's own type. On the other hand, a match with a higher type spouse does not yield sufficient gains to marriage for the man to offer the minimum utility to attract her. This process is depicted as a fall in $\widehat{u}\left(t_{w}, k, n \mid t_{h}(H)\right)$ for a man of type $t_{h}(H)$, noting

\footnotetext{
${ }^{17}$ Anderson and Leo (2009) examined the effects on intergenerational mobility as a result of the OCP.
} 
further that for a substantial fall in the utility of the man from marriage, he might not be able to attract spouses of higher types. On the other hand, for a sufficiently low type man, this may even mean a complete withdrawal from the marriage market, depicted as a fall in $u\left(t_{w}, k, n \mid t_{h}(M)\right)$ for a man of type $t_{h}(M)$ in figure 3 . The latter observation is reflected in the following corollary.

Corollary 1 : A binding Family Size Policy which reduces the number of children born into a family reduces the marriage rate for all types of men.

Figure 3: Impact of Binding Family Size Policy on Spousal Type

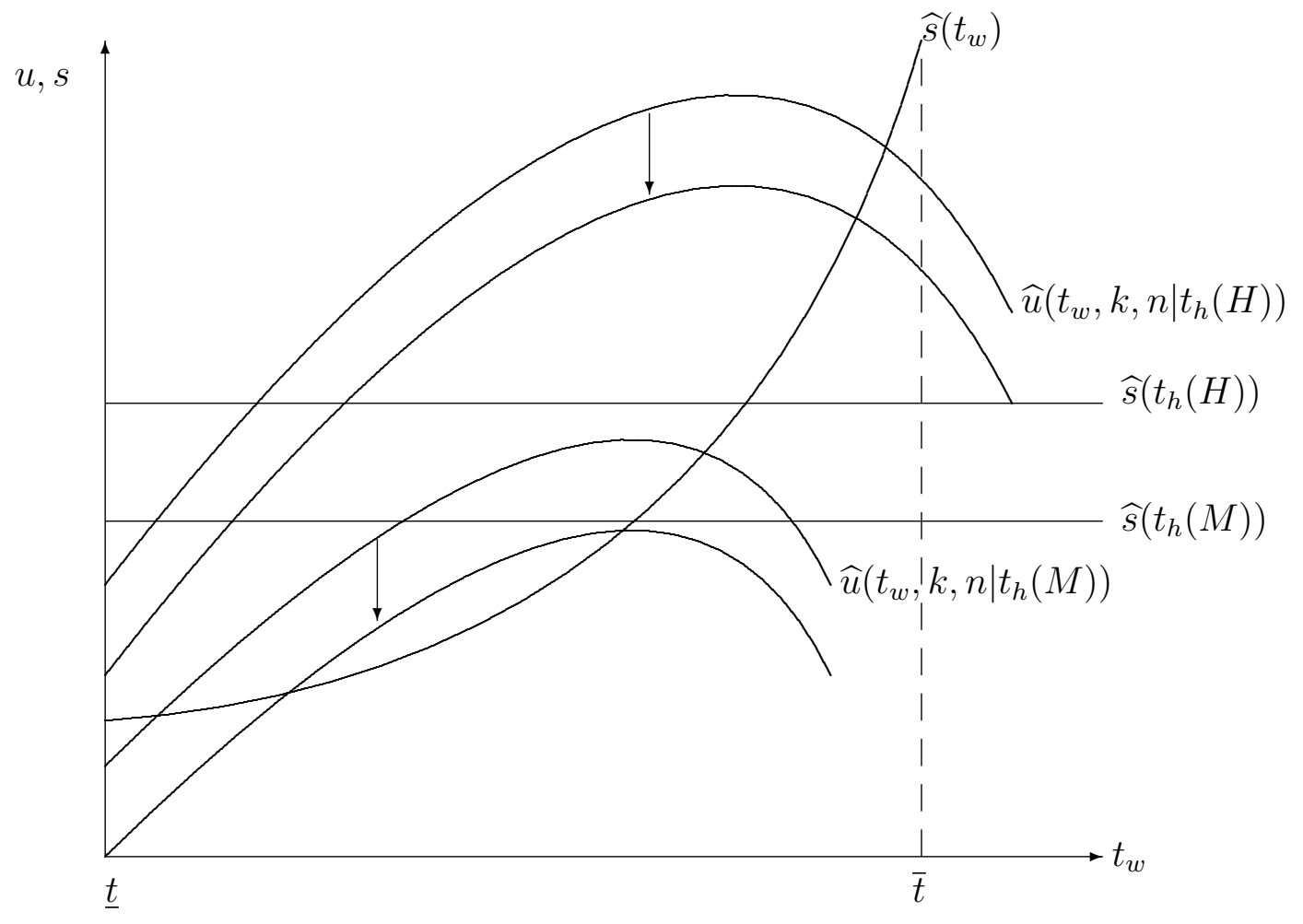

On the other hand economic growth, by raising disposable income, could potentially slacken the need for a good spousal match. However, at the same time, economic growth may have also raised the gains to remaining single, thereby reducing the merits of marriage in the first place.

Proposition 4: An increase in $y$, the average (real) income in the economy, leads to the following: 
1. for all men, the lower bound on the reservation type of a prospective spouse would fall, while the upper bound would rise and,

2. agents who choose to marry would exhibit decreased assortative matching.

If at the status quo on the margin of spousal type, the man is indifferent to marrying or remaining single, an increase in income available to him cannot make his potential spouse any less attractive. However, if it makes her more attractive, by increasing his utility, the marginal prospective spousal type at the lower bound must fall, while the upper bound must increase. (This outcome is facilitated by the assumption that an increased average income within the economy has no redistributive effects, so growth results in a shift of the entire distribution to a new mean income level, while maintaining its shape). The corollary below follows:

Corollary 2 An increase in average income increases marriage rates.

Finally to show that the marriage market clears, since each individual meets only one potential spouse in their lifetime, and marriage takes place only if the potential spouse is within the reservation attributes, the probability of marriage for a man of type $t_{h}$ is $P$ such that,

$$
P=\operatorname{Pr}\left(\underline{t_{w}^{R}} \leq t_{w} \leq \overline{t_{w}^{R}}\right)=\int_{\underline{t_{w}^{R}}}^{\overline{t_{w}^{R}}} f\left(t_{w}\right) d t_{w}=F\left(\overline{t_{w}^{R}}\right)-F\left(\underline{t_{w}^{R}}\right)
$$

It is clear that $P \in[0,1]$. Let there be a unit mass of males and females. Then the marriage rate in the marriage market $M$ is,

$$
\begin{aligned}
M & =\int_{\underline{t}}^{\bar{t}}\left\{F\left(\overline{t_{w}^{R}}\left(t_{h}\right)\right)-F\left(\underline{t_{w}^{R}}\left(t_{h}\right)\right)\right\} f\left(t_{h}\right) d t_{h} \\
& <\left\{F\left(\overline{t_{w}^{R}}(\bar{t})\right)-F\left(\underline{t_{w}^{R}}(\bar{t})\right)\right\} \int_{\underline{t}}^{\bar{t}} f\left(t_{h}\right) d t_{h} \\
& =\left\{F\left(\overline{t_{w}^{R}}(\bar{t})\right)-F\left(\underline{t_{w}^{R}}(\bar{t})\right)\right\}<1
\end{aligned}
$$

from which it is clear that $M \in[0,1]$ and the market clears.

The model has examined two direct venues through which matching in the marriage market could have been affected, through constraining family size by the OCP and the 
increase in income by the Economics Reforms. However other possible venues through which both policies could have affected matching should be acknowledged, at least conceptually. One possible indirect effect that may affect matching via the Economic Reforms is through changes in the returns to education. Essentially as the gains to human capital investment increase, the marginal density of attribute realizations for both sides of the marriage market will be altered. This would necessarily alter the probability of an individual meeting her potential spouse over the entire range of potential spouses in the marriage market, but not the desired choice set itself which is what this paper examines and attempts to measure. The same can be said about the OCP, since among parents who are cognizant of its effects on the gains to marriage and, given that a "good" marriage entered into by their children would raise their own utility, it is in their own interests to ensure that their children's potential gains to marriage do not suffer (See for example Peters and Siow (2002) for a model on premarital investments in children).

\section{Description of Data}

The observations for the empirical analysis are drawn from a bi-annual urban household survey of six provinces in China from 1989 to 2001; Shaanxi, Jilin, Hubei, Sichuan, Guangdong and Shandong 18 , The matching attribute examined is educational attainment, the classification of which is based on the pre-1986 eight year compulsory educational system since the youngest set of individuals in our sample, those born in 1969 would have completed their compulsory education prior to the implementation of the new educational laws 19 . Specifically, educational attainment is integer indexed from 1 to 5 , with 5 representing college graduates and above, 4 for individuals with technical education, 3 for high school, 2 for middle school, and 1 for primary school and below.

The sample is divided into 3 cohorts, the first are couples with husbands born between 1940 and 1949, the second cohort have husbands born between 1950 and 1959, and the last from 1960 to 1969. This was done because the empirical joint density matrix generated

\footnotetext{
${ }^{18}$ This data was obtained from the National Bureau of Statistics as part of the project on Income Inequality during China's Transition organized by Dwayne Benjamin, Loren Brandt, John Giles and Sangui Wang.

${ }^{19}$ China implemented a nine year compulsory educational system, divided into primary (five to six years) and junior secondary (3 to 4 years). Upon completion, the children may then attend senior secondary lasting 3 years. China Education and Research Network.
} 
Table 1: Summary of Parental Characteristics

\begin{tabular}{|c|c|c|c|c|c|c|c|}
\hline \multirow[t]{2}{*}{ Province } & \multirow[t]{2}{*}{ Variable } & \multicolumn{2}{|c|}{ 1940s Cohort } & \multicolumn{2}{|c|}{ 1950s Cohort } & \multicolumn{2}{|c|}{ 1960s Cohort } \\
\hline & & Mean & S.D. & Mean & S.D. & Mean & S.D. \\
\hline \multirow[t]{4}{*}{ Jilin } & Number of Children & 1.3547 & 0.8333 & 1.1550 & 0.4618 & 0.9904 & 0.2753 \\
\hline & Father's Education & 3.1818 & 1.3794 & 3.1741 & 1.1636 & 3.4738 & 1.1559 \\
\hline & Mother's Education & 2.7004 & 1.2614 & 3.0165 & 1.0724 & 3.3311 & 1.0927 \\
\hline & Observations & \multicolumn{2}{|c|}{1342} & \multicolumn{2}{|c|}{2723} & \multicolumn{2}{|c|}{1661} \\
\hline \multirow[t]{4}{*}{ Shandong } & Number of Children & 1.4867 & 0.7726 & 1.1478 & 0.3971 & 1.0182 & 0.2585 \\
\hline & Father's Education & 3.1128 & 1.3216 & 3.3286 & 1.2541 & 3.8288 & 1.1336 \\
\hline & Mother's Education & 2.5531 & 1.2518 & 2.9259 & 1.1048 & 3.3512 & 1.0745 \\
\hline & Observations & \multicolumn{2}{|c|}{1206} & \multicolumn{2}{|c|}{2970} & \multicolumn{2}{|c|}{1922} \\
\hline \multirow[t]{4}{*}{ Hubei } & Number of Children & 1.4012 & 0.7608 & 1.1157 & 0.4023 & 0.9927 & 0.2229 \\
\hline & Father's Education & 3.1812 & 1.3377 & 3.2202 & 1.2133 & 3.7847 & 1.1258 \\
\hline & Mother's Education & 2.5248 & 1.2449 & 2.8931 & 1.0500 & 3.3681 & 1.0865 \\
\hline & Observations & \multicolumn{2}{|c|}{1649} & \multicolumn{2}{|c|}{3397} & \multicolumn{2}{|c|}{1649} \\
\hline \multirow[t]{4}{*}{ Guangdong } & Number of Children & 1.5875 & 0.7460 & 1.1696 & 0.4427 & 1.0152 & 0.3327 \\
\hline & Father's Education & 3.0413 & 1.4145 & 3.2011 & 1.2509 & 3.6340 & 1.0717 \\
\hline & Mother's Education & 2.4732 & 1.2586 & 2.9261 & 1.0687 & 3.3612 & 1.0666 \\
\hline & Observations & \multicolumn{2}{|c|}{1549} & \multicolumn{2}{|c|}{2760} & \multicolumn{2}{|c|}{1254} \\
\hline \multirow[t]{4}{*}{ Sichuan } & Number of Children & 1.0647 & 0.7603 & 1.0133 & 0.3501 & 0.9744 & 0.2563 \\
\hline & Father's Education & 3.1247 & 1.3725 & 2.9652 & 1.3065 & 3.6205 & 1.1736 \\
\hline & Mother's Education & 2.5109 & 1.2525 & 2.7036 & 1.0942 & 3.3821 & 1.1050 \\
\hline & Observations & \multicolumn{2}{|c|}{2165} & \multicolumn{2}{|c|}{4514} & \multicolumn{2}{|c|}{2308} \\
\hline \multirow[t]{4}{*}{ Shaanxi } & Number of Children & 1.3491 & 0.8425 & 1.1680 & 0.4827 & 1.0118 & 0.3199 \\
\hline & Father's Education & 3.2498 & 1.2991 & 3.2704 & 1.2642 & 3.6171 & 1.1439 \\
\hline & Mother's Education & 2.6821 & 1.1480 & 2.8971 & 1.0208 & 3.1988 & 1.0151 \\
\hline & Observations & \multicolumn{2}{|c|}{1249} & \multicolumn{2}{|c|}{1827} & \multicolumn{2}{|c|}{1016} \\
\hline
\end{tabular}

1=Elementary School \& Lower, 2=Middle School, 3=High School, 4=Technical

Education, $5=$ College

with the assumption that offers of marriage are made by men to women, yielded a closer overlap with the observed joint density matrix. The first cohort is construed as the preOCP cohort, the last being the post-OCP cohort, with the 1950s cohort straddling the OCP. Finally, we assumed that marriage markets are closed within each province, so the analysis will proceed by province.

Table 1 summarizes some of the characteristics of married couples within our sample. Notice the ubiquitous fall in the number of children over the decades, and particularly among the 1960s cohort. In addition, note the increase in educational attainment over the 
decades which may be due to increased returns to education with the economic reforms, or it could be from increased investments in children by parents as discussed earlier, or simply due to the regime shift from post-Cultural Revolution China.

\subsection{Is the OCP a Binding Constraint?}

To establish the notion that the OCP constituted a binding constraint to the 1960s cohort, table 2 reports the results for a simple Poisson model of the number of children a couple has subsequent to their first child. The first order effect of the OCP is to curtail the demand for children, consequently it may be conjectured that the presence of any additional children after the first child is likely an "accident", which underlies the Poisson model. The first panel relates to the three cohorts without conditioning on the gender of the first child, the second and third panels report the results when it is a male and female respectively.

From the first panel, the Poisson "accidents" model is rejected for all provinces at the $1 \%$ level for the 1940s cohort, but the 1950s and 1960s cohorts yielded only two rejections of the model (Guangdong for the 1950s cohort and Shaanxi for the 1960s cohort). When the sample is differentiated by the gender of the first born, the same results prevail among male first born. However, among female first born families, the model is rejected for all provinces for the 1940s cohort, and not rejected for all provinces for the 1950s and 1960s cohorts. Overall these results are evidence that post-OCP births after the first child are well described by a Poisson accidents model and confirms the efficacy of the OCP.

Parenthetically, although it was not addressed in the model, the data may shed light on the gender selection issue, which may in itself affect the equilibrium marriage rates. Table 3 presents Standard Normal Tests of the null hypothesis that the proportion of first born children that are male is at most that of the natural rate. The hypothesis is rejected for the 1940s cohort at the $5 \%$ level in 4 of the 6 provinces, but it is rejected only once for the 1950s cohort (for Sichuan) and twice in the 1960s cohort (for Shandong and Guangdong), which is not sufficient evidence to suggest that the OCP had exacerbated the gender selection issue for our urban sample.

\footnotetext{
${ }^{20} \mathrm{~A}$ possible explanation is the observed reduction in obstetrics care usage (Doherty et al. 2001) subsequent to the OCP.
} 


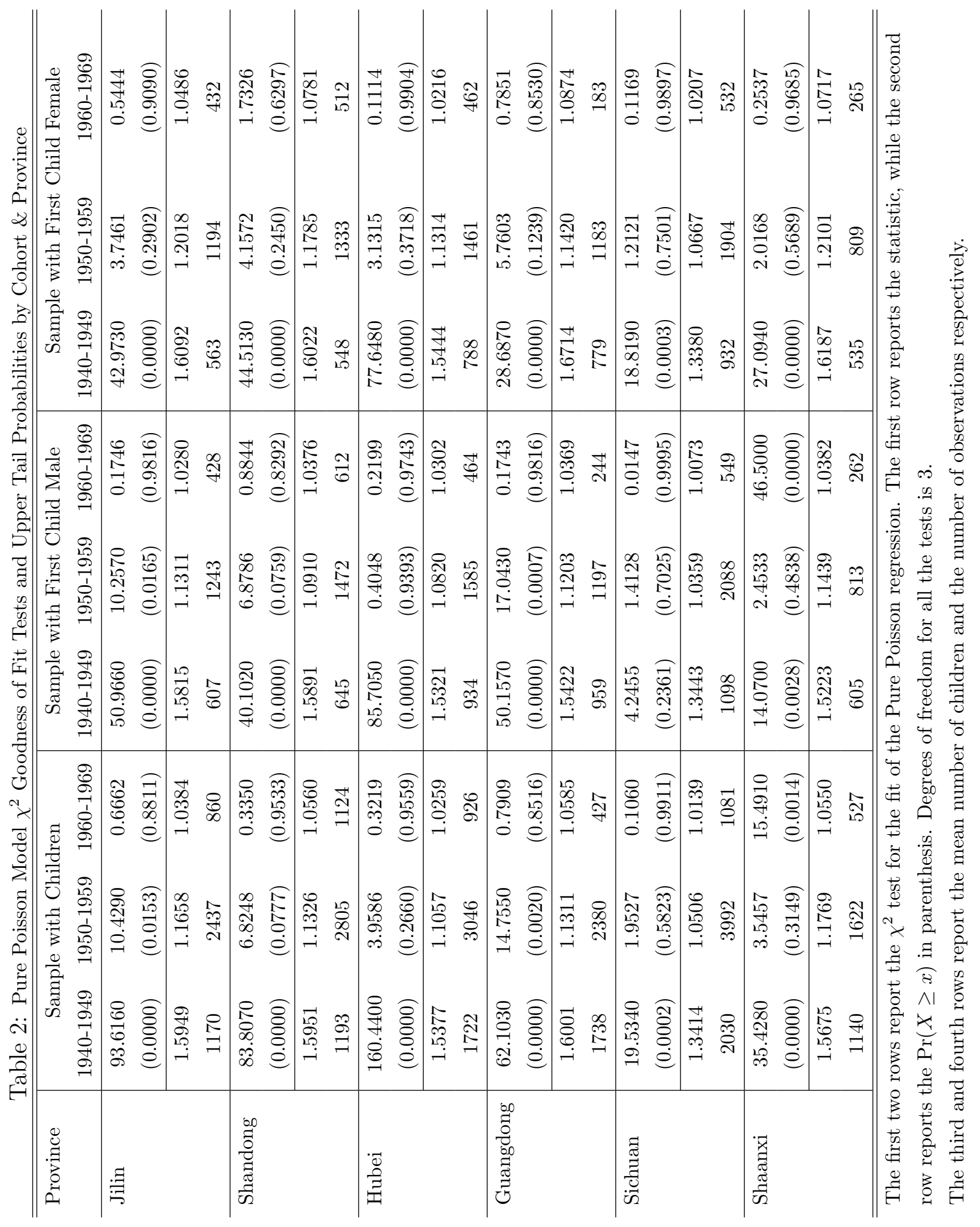


Table 3: Standard Normal Test Statistics $\left(H_{0}\right.$ : The proportion of first born children that are male is less than or equal to the natural rate of $\left.\frac{104}{100}\right)$

\begin{tabular}{l|ccc}
\hline \hline Province & 1940 s Cohort & 1950s Cohort & 1960s Cohort \\
\hline Jilin & 0.6158 & 0.0246 & -0.7116 \\
& {$[0.2690]$} & {$[0.4902]$} & {$[0.7616]$} \\
\hline Shandong & 2.1315 & 1.5863 & 2.3258 \\
& {$[0.0165]$} & {$[0.0563]$} & {$[0.0100]$} \\
\hline Hubei & 2.7052 & 1.1648 & -0.5310 \\
& {$[0.0034]$} & {$[0.1220]$} & {$[0.7023]$} \\
\hline Guangdong & 3.5009 & -0.6697 & 2.5473 \\
& {$[0.0002]$} & {$[0.7485]$} & {$[0.0054]$} \\
\hline Sichuan & 2.8014 & 1.6737 & -0.1276 \\
& {$[0.0025]$} & {$[0.0471]$} & {$[0.5508]$} \\
\hline Shaanxi & 1.4115 & -0.6905 & -0.5809 \\
& {$[0.0791]$} & {$[0.7551]$} & {$[0.7194]$} \\
\hline \hline
\end{tabular}

$\operatorname{Pr}(Z \geq z)$ are in brackets

Table 4: Standard Normal Test Statistics $\left(H_{0}\right.$ : No Difference Between Number of Children Given First Child Male and Female)

\begin{tabular}{l|ccc}
\hline \hline Province & $\Delta$ for 1940s Cohort & $\Delta$ for 1950s Cohort & $\Delta$ for 1960s Cohort \\
\hline Jilin & -0.7510 & -4.4887 & -1.5708 \\
& {$[0.7736]$} & {$[1.0000]$} & {$[0.9417]$} \\
\hline Shandong & -0.3531 & -6.6330 & -2.9030 \\
& {$[0.6380]$} & {$[1.0000]$} & {$[0.9981]$} \\
\hline Hubei & -0.4227 & -4.1360 & 0.8160 \\
& {$[0.6637]$} & {$[1.0000]$} & {$[0.2074]$} \\
\hline Guangdong & -3.9103 & -1.3907 & -2.2090 \\
& {$[1.0000]$} & {$[0.9178]$} & {$[0.9862]$} \\
\hline Sichuan & 0.2578 & -4.3960 & -1.8830 \\
& {$[0.3983]$} & {$[1.0000]$} & {$[0.9700]$} \\
\hline Shaanxi & -2.4423 & -3.2883 & -1.4851 \\
& {$[0.9926]$} & {$[0.9995]$} & {$[0.9310]$} \\
\hline \hline
\end{tabular}

$\operatorname{Pr}(Z \geq z)$ are in brackets 
The analysis can be taken further by comparing the number of children after the first child, conditioning on the gender of that child. The suggestion here is that for at least the 1950s and 1960s cohorts, if the desire for male offspring was prevalent, but children subsequent to the first were "accidents", a first child being female would increase the chance of such an "accident" occurring. Table 4 presents the Standard Normal Tests for that comparison. At the $5 \%$ level of significance, households in two provinces amongst the 1940s cohort had significantly more children if their first born was female, while it was 5 provinces amongst the 1950s cohort households. The suggested upward trend stands in contrast to the 1960s cohort households with 3 provinces showing the same propensity.

Thus it may be concluded that the OCP or modernization appears to not have exacerbated the traditional male child preference in that the degree to which the $\frac{\text { male }}{\text { female }}$ first birth ratio is skewed has diminished. This is perhaps not surprising since there is some evidence that pre-natal and obstetrics care usage had fallen subsequent to the OCP(Doherty et al. 2001). As far as subsequent children are concerned, it seemed to initially increase the propensity for an "accident" amongst families whose first child was female amongst the 1950s cohort, but this had returned to pre-OCP levels by the 1960s. Nonetheless, it must be emphasised that families with more than one child for later cohorts are only a small proportion of the total sample, revealing the efficacy of the OCP.

\subsection{Capacity for Assortative Matching}

The extent to which the OCP influenced partner choice decisions depends upon the degree to which positive or negative assortative pairing prevailed prior to the inception of the OCP and how it changed thereafter. The comparative statics predict an increase in the incidence of positive assortative matching (decrease in negative assortative matching) with the onset of the OCP, in the sense that the range of values of a particular attribute an individual is willing to entertain in a partner has narrowed around his own attribute realization. It also predicts a drop in the marriage rate. However these predictions need qualification in terms of the supply and demand conditions within the marriage market. In other words, they are always predicated on the availability of desirable partners. 


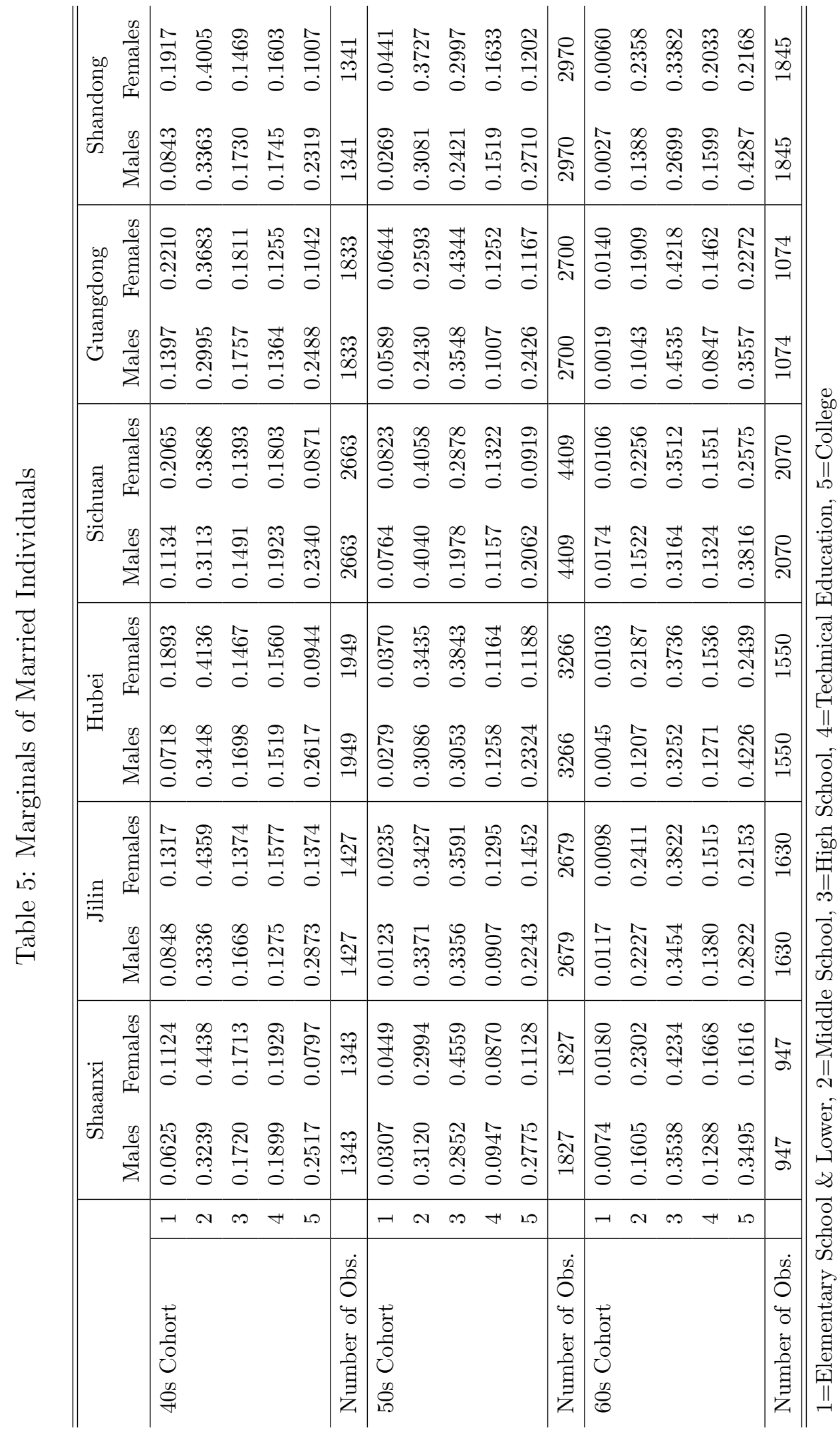


Table 5 summarizes the distribution of educational attainment by gender and province for married individuals in the three birth cohorts. Notice the marginal distributions of male attainments stochastically dominate those of females. It is then to be expected that if marriage is indeed beneficial, well educated men in the earlier birth cohorts may adapt through lower incidences of positive assortative matching choices ${ }^{21}$. As attainment rose among the general populace, the possibility of increase positive assortative matching would have increased among men with higher attainment. This upward trend in educational attainment among married individuals is not an effect of the OCP or Economic Reforms on familial investments in children since the they were born of parents in an era prior to 1979. Nonetheless this means that we have to be aware of trends in assortative matching in identifying the effect of the OCP.

Overlap amongst the male and female attainment distributions (the sum of the minimums of the male and female proportions in each attainment category) is a measure of the degree to which perfect positive assortative matching is feasible. Such an overlap measure for each province and the three cohorts are respectively; Jilin was 0.8146, 0.9204 and 0.9320; Shandong was 0.8333, 0.8494 and 0.7907; Hubei was 0.8069, 0.8775 and 0.8210; Guangdong was 0.8447, 0.8740 and 0.8403; Sichuan was 0.8278, 0.8865 and 0.8705; and Shaanxi was $0.8241,0.8149$ and 0.8109 . There was thus an increase in the potential for assortative pairing between the 1940s and 1950s cohorts in all the provinces (with the exception Shaanxi). On the other hand, there was a decrease in potential with the exception of Jilin for the comparison between the 1950s and 1960s cohorts. This suggests that should a significant increase in assortative pairing between the 1950s and 1960s cohorts be found, it is very possible that it is due to the OCP.

\section{$5 \quad$ Testing the Matching Hypotheses}

\subsection{Empirical Strategy}

Besides the predictions of the previously discussed model in section 3, there are additional elements that will serve to identify the effects of the OCP. Firstly, the noted changes in the capacity for positive assortative matching can help identify the cause. For example if we observe an increase in positive assortative matching in the face of a decrease capacity,

\footnotetext{
${ }^{21}$ Due to a lack of data, we are also unable to discern if the individuals were married in rural towns prior to being observed within the urban context.
} 
it would suggest that the OCP could be the underlying cause. Secondly, the differential impact of both the OCP and Economic Reforms across provinces allows the use interprovincial differences in intensity of positive assortative matching to identify the cause of the change. Finally, since the OCP and Economic Reforms affected about half of the samples, the differences across cohorts will likewise help in identification.

To elaborate, since a priori it is not known if positive or negative assortative matching existed as the status quo, to conclude that positive assortative matching rose, it has to be ascertained that there was a significant increase in overlap between the empirical joint density and perfect positive assortative density, coupled with a significant decrease in overlap between the empirical joint density and perfect negative assortative density, across the cohorts. In other words, the hypotheses that will be tested for each province are:

$$
\text { vs. } \begin{aligned}
& H_{0}: \Delta \mathbf{O V}_{p}=\mathbf{O V}_{p}^{t}-\mathbf{O V}_{p}^{t^{\prime}} \geq 0 \\
& H_{1}: \Delta \mathbf{O V}_{p}=\mathbf{O V}_{p}^{t}-\mathbf{O V}_{p}^{t^{\prime}}<0
\end{aligned}
$$

and decreased negative assortative matching via:

$$
\text { vs. } \begin{aligned}
& H_{0}: \Delta \mathrm{OV}_{n}=\mathrm{OV}_{n}^{t}-\mathrm{OV}_{n}^{t^{\prime}} \leq 0 \\
& H_{1}: \Delta \mathrm{OV}_{n}=\mathrm{OV}_{n}^{t}-\mathrm{OV}_{n}^{t^{\prime}}>0
\end{aligned}
$$

where $t, t^{\prime} \in\{1940 s, 1950 s, 1960 s\}$.

Further for each province, comparisons of the difference in the changes in assortative matching patterns and it's intensity, allows us to examine the trends in matching. In the absence of any trends towards positive assortative matching (possibly as a result of preference for smaller family sizes due to urbanization), changes in the matching pattern could be due to either the OCP or Economic Reforms. However, should there be a "linear" trend towards positive assortative matching, the effect that is due to the OCP or the Economic Reforms can be gleaned from examining the difference in the measures from two comparisons, 1940s versus 1960s, and 1950s versus 1960s, which is similar to a difference-in-difference analysis.

\subsection{Results}

The empirical joint densities of the data are reported in Table 6. Notice the diagonal probabilities of the joint densities provide some evidence of increased assortative pairing 
between the cohorts born in the 1940s and 1950s which is not surprising given the capacity for assortative matching has increased between the two cohorts (The comparison between these two cohorts is akin to examining the marital effects due to the Cultural Revolution between 1966 and 1969.). Interestingly, this was also true among provinces where capacity for positive assortative pairing for the 1960s cohort decreased. Closer inspection of the marginal densities in table 5 shows that the fall in capacity is due to the decrease in proportion of low educational attainment individuals, while the increases in positive asortative pairing among the 1960s cohorts are among individuals with higher attainment. Further, as predicted by the model, the rates of matching among individuals of low attainment fell. Nonetheless, this evidence is only suggestive in nature.

The corresponding indices and tests for positive and negative assortative matching using the overlap measure are reported in Table 7. It must be noted that because the 1950s cohort consists of mainly individuals who made their spousal choice prior to the implementation of the OCP, while the 1960s cohort were those most likely affected, the identification of the impact of the OCP hinges on the increase in assortative pairing by the 1960s cohort over the other two cohorts.

From table 7 note that in all instances, the overlap measures are all statistically significantly different from complete overlap, and that the empirical joint density is a closer match to the positive assortative joint density. Examining the change in assortative matching between the 1940s and 1950s cohort, the hypothesis of increased positive assortative matching, and decreased negative assortative matching cannot be rejected for Shandong, Hubei, Guangdong, and Sichuan. For Jilin and Shaanxi, it seems there is an increase in both positive and negative assortative matching. Nonetheless, the positive assortative hypothesis remains a better description of the empirical joint densities. Considering the fact that the capacity for positive assortative matching rose between the two cohorts, the outcomes are not surprising and may be explained as the effects of increased educational attainment in the general populace, and a trend towards increased positive assortative matching. 


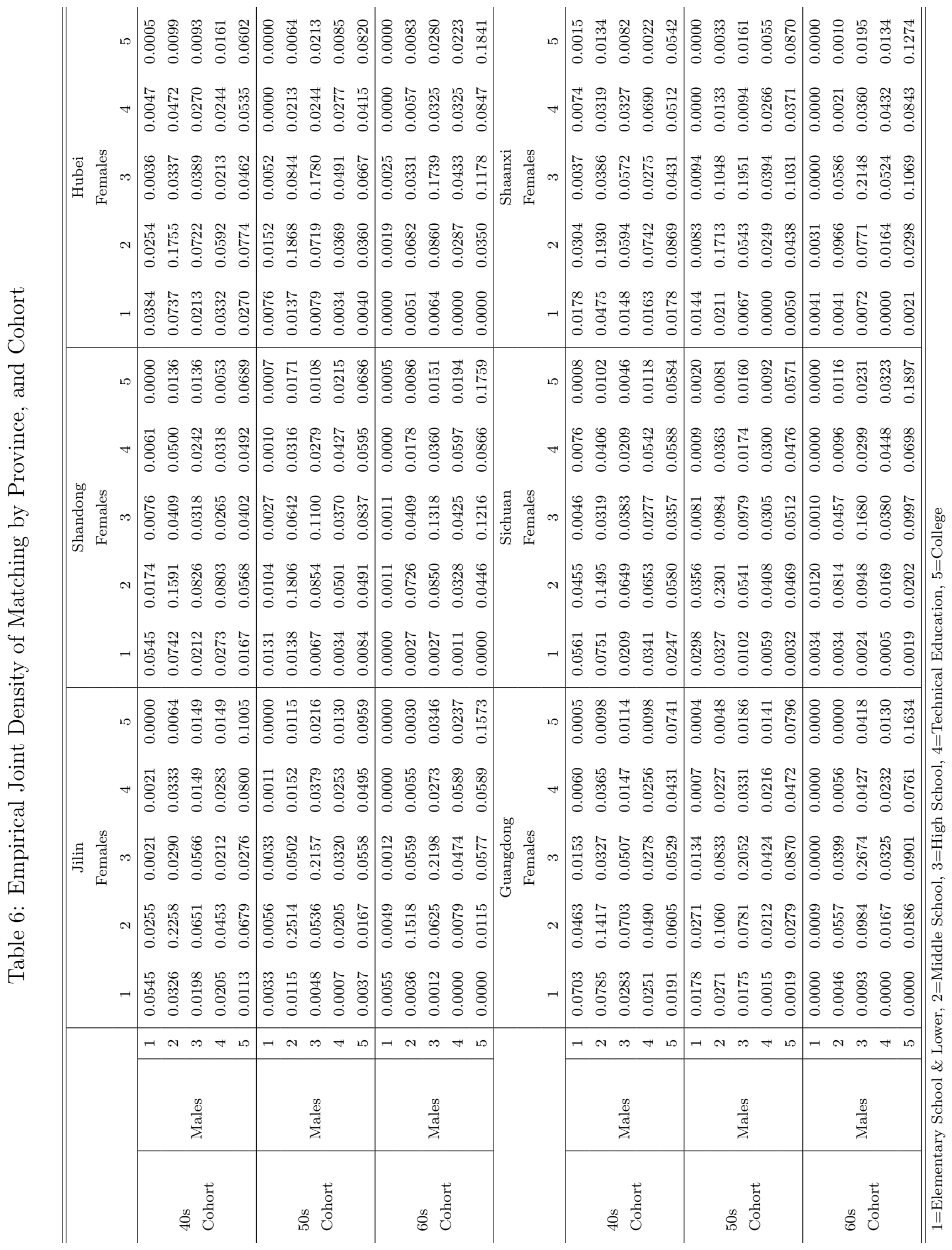




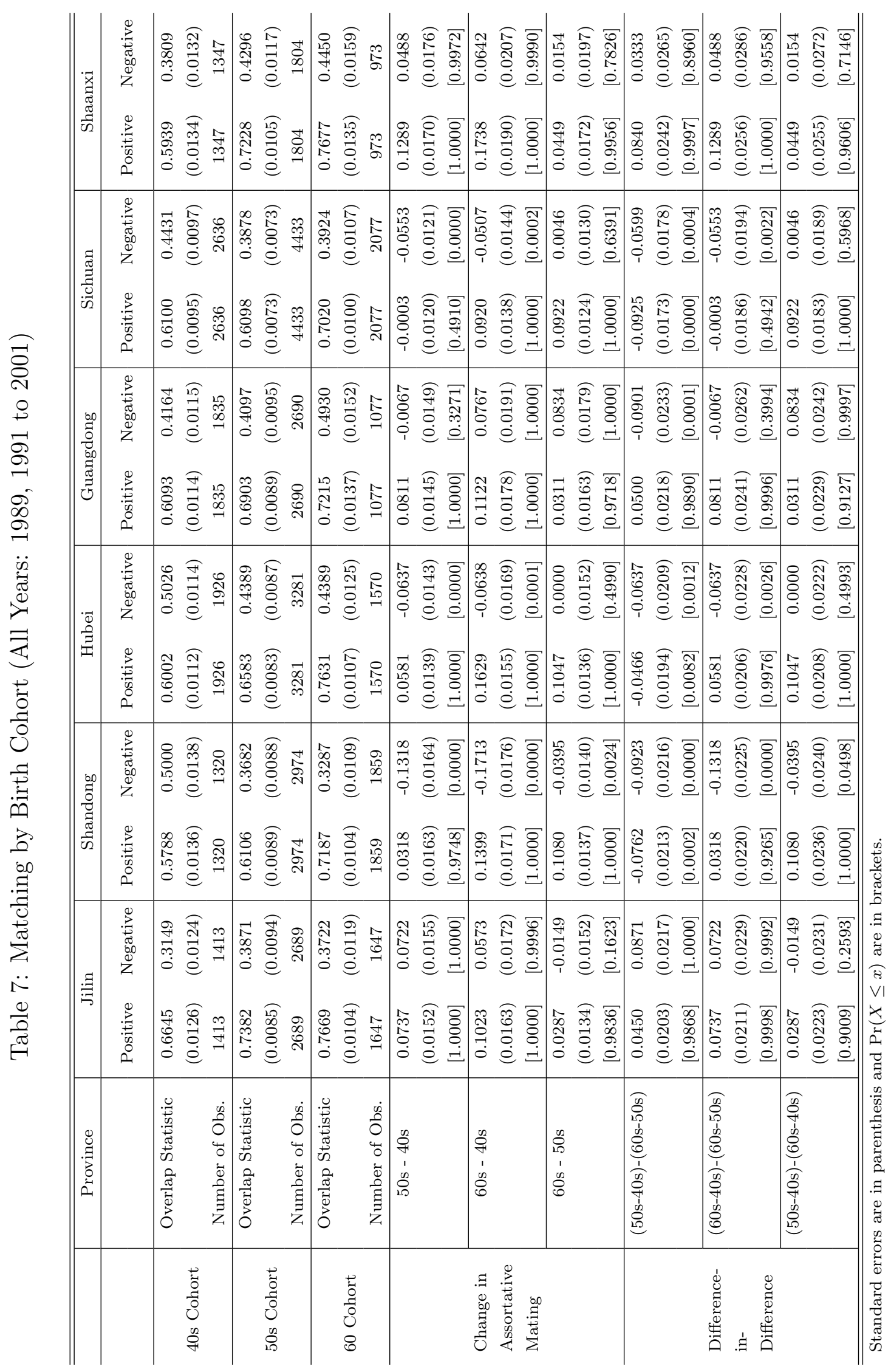


For the comparison between the 1950s and 1960s cohorts, notice the significant increase in positive assortative matching but insignificant change in negative assortative matching for Jilin, Hubei, Sichuan and Shaanxi. Shandong saw a significant increase in positive assortative matching and a decrease in negative assortative matching, while Guangdong recorded a significant increase in both positive and negative assortative matching, with the overlap with positive assortative joint density being higher. Similar conclusions can be made when comparing the 1960s and 1940s cohorts. This significant increase in positive assortative matching in the 1960s, negating considerations of trends and coupled with the decreased capacity for positive assortative matching among the 1960s cohort, suggests that it is a consequence of the OCP or that it's effects dominate.

The results examining the relative change in Overlap between two comparisons are reported in table 7, essentially controlling for trends towards increased positive assortative matching. Since all the provinces here had experienced an increase in capacity for positive assortative matching between the 1940s to the 1950s (with the exception of Shaanxi), we can test whether the increase in positive assortative matching between the 1950s and 1960s cohorts is significantly greater than that between the 1940s and 1950s. This is the primary comparison since the increase in capacity between the 1940s and 1950s is the largest, and should overstate the trend towards positive assortative matching. On the other hand, due to the proximity in time between the 1950s and 1960s cohort, it should understate the effect of the OCP. This comparison is reported in the first comparison of the final panel under "Difference-in-Difference".

Since Shandong, Hubei and Sichuan all experienced a significantly higher rate of increase in positive assortative matching between the 1950s and 1960s cohorts despite the fall in capacity, the results suggest that the increase in positive assortative matching is a result of the OCP. On the other hand, Guangdong and Shaanxi experienced a significant slow down in positive assortative matching. The obvious reason is the fall in capacity for positive assortative matching for both province amongst the 1960s cohort. In addition, Guangdong was and continues to be a key beneficiary of economic growth, which would have particularly affected the 1950s and 1960s cohorts. In other words, the fall in positive assortative matching there would be tempered by the income effect. For Jilin, the only province in our sample that exhibited continued increase in capacity, much of the increase in positive assortative matching seem to have been exhausted by the arrival of the 1950s cohort. So for Shaanxi and Jilin, the dominating effect that drove the change in positive 
assortative matching is due to trends (in post Cultural Revolution China) and/or urbanization. On the aggregate, there is suggestive evidence supporting the hypothesis that the OCP altered matching patterns in the marriage market.

As an supplement to the above discussion, if the OCP indeed induced an increase in positive assortative matching, it would also reduce the likelihood of a high attainment individual choosing the lower attainment individuals as partners. This means that there may be a stochastic dominant shift in the cumulative distribution of spouses across the cohort: 22 . This was affirmed by the data among the higher attainment group 23 . For the lower educational attainment realizations, the analysis is complicated by the shrinkage of the attainment support.

\section{Conclusion}

Although there has been much significant work on estimating Becker's (1973) theory of matching, work related to testing the predictions is still preliminary in nature. Generally little has been done in developing indices with known statistical properties that can be used to test matching theories. This paper fills that important void by presenting a matching index, the Overlap Measure developed by Anderson et al. (2010), that is amenable to the examination of differing matching theories with respect to observed matching patterns, and facilitates inference due to its asymptotically Normal properties.

In demonstrating the measure's ease of use, the paper examined the possibility that the One Child Policy (OCP) instituted in China in 1979 affected matching patterns, a question that has not yet received consideration. Due to potential confounding effects arising from the concurrent Economic Reform policy of 1979, this paper developed a static general equilibrium model that examines how the two policies could have competing effects on matching in the marriage market.

It is well understood that marital output has several dimensions and that when one dimension is exogenously constrained below the private optimal choice, agents adjust in other dimensions. What is perhaps less well understood is that the imposition of such a constraint may change the way agents choose their spouses. Here the consequences for

\footnotetext{
${ }^{22}$ The authors thank Aloysius Siow for suggesting this alternative approach.

${ }^{23} \mathrm{~A}$ complete discussion of the implications of the model regarding stochastic dominance, and the stochastic dominance test results are available from the authors upon request.
} 
partner choice due to the imposition of the OCP on the Chinese populace in 1979 have been examined in terms of the urban populations in six provinces. As a guide to the analysis, the model of family formation developed predicts an increase in the marginal benefits and consequently incidence of positive assortative matching, but a reduction in the number of matches and the increase in investment in child quality. Importantly for identification reasons, the model also predicts a reduction in the intensity of positive assortative matches with economic growth.

The matching predictions were empirically examined via bi-annual samples of urban households in six Chinese provinces taken from 1987 through 2001. The index developed for measuring the intensity of positive assortative matching was based upon the degree of overlap between the hypothetical perfectly positive assortative and empirical joint density of matches, on the single dimension of educational attainment. By pooling the samples into three cohorts, those who made family structure decisions prior to the OCP, those whose decisions spanned the introduction of the OCP and those whose decisions were made after the OCP, it was possible to evaluate how matching patterns changed over the introduction of the OCP.

After establishing, via a Poisson "accidents" model, that the OCP did present a binding constraint to families who desired more than one child ${ }^{24}$, the intensity of positive and negative assortative matching was examined. The index indicated significant increases (decreases) in the intensity of positive (negative) assortative matching, and this was accompanied by a significant reduction in the incidence of marriage, all of which accorded with the predictions of the model. Thus the evidence here suggests that the OCP may have precipitated an increase (decrease) in positive (negative) assortative matching.

\footnotetext{
${ }^{24} \mathrm{~A}$ bi-product of this analysis was evidence that the OCP suppressed the extent to which gender selection of children occurred, though there was evidence that the probability of having an "accident" after a female first born was greater than the probability of an "accident" after a male first born.
} 


\section{References}

Abowd, John M., Francis Kramarz, and David N. Margolis, "High Wage Works and High Wage Firms," Econometrica, 1999, 67 (2), 251-334.

Anderson, Gordon, "Nonparametric Tests of Stochastic Dominance in Income Distributions," Econometrica, 1996, 64, 1183-1193.

and Teng Wah Leo, "Child Poverty, Investment in Children and Generational Mobility: The Short and Long Term Wellbeing of Children in Urban China after the One Child Policy," Review of Income and Wealth, 2009, 55 (s1), 607-629.

and Ying Ge, "The size distribution of Chinese cities," Regional Science and Urban Economics, 2005, 35 (6), 756-776.

, Oliver Linton, and Yoon-Jae Whang, "Nonparametric Estimation of a Polarization Measure," 2009. University of Toronto Manuscript.

, Ying Ge, and Teng Wah Leo, "Distributional Overlap: Simple, Multivariate, Parametric and Non-Parametric Tests for Alienation, Convergence and General Distributional Difference Issues," Econometric Reviews, 2010, 29 (3), 247-275.

Atakan, Alp, "Assortative Matching with Explicit Search Costs," Econometrica, 2006, 74, 667-680.

Atkinson, Anthony, "On the Measurement of Inequality," Journal of Economic Theory, 1970, 2, 244-263.

Becker, Gary, "A Theory of Marriage: Part I," Journal of Political Economy, 1973, 81, 813-846.

— , Treatise on the Family 1993. Harvard University Press.

Bergstrom, Theodore and David Lam, "The Effects of Cohort Size on Marriage Markets in Twentieth Century Sweden," in The Family, the Market, and the State in Ageing Societies, 1994, pp. 46-63. edited by John Ermisch and Naohiro Ogawa.

Bourguignon, Francois and Gary Fields, "Discontinuous Losses from Poverty, Generalized Measures, and Optimal Transfers to the Poor," Journal of Public Economics, 1997, 63, 155-175. 
Browning, Martin, "Children and Household Economic Behavior," Journal of Economic Literature, 1992, 30, 1434-1475.

Burdett, Ken and Melvyn Coles, "Marriage and Class," Quarterly Journal of Economics, 1997, 112 (1), 141-168.

Caldwell, John, Theory of Fertility Decline 1982. London Academic Press.

Choo, Eugene and Aloysius Siow, "Estimating a Marriage Matching Model with Spillover Effects," Demography, 2006, 43 (3), 463-488.

and _ , "Who marries whom and why," Journal of Political Economy, 2006, 114 (1), 175-201.

Dagsvik, John, "Aggregation in Matching Markets," International Economic Review, 2000, $41(1), 27-57$.

Damiano, Ettore, Hao Li, and Wing Suen, "Unravelling of Dynamic Sorting," Review of Economic Studies, 2005, 72 (4), 1057-1076.

Dardanoni, Valentino, "On Measuring Social Mobility," Journal of Economic Theory, 1993, 61, 372-394.

Davidson, Russell and Jean-Yves Duclos, "Statistical Inference for Stochastic Dominance and for the Measurement of Poverty and Inequality," Econometrica, 2000, 68, $1435-1464$.

de Melo, Rafael Lopes, "Sorting in the Labor Market: Theory and Measurement," 2008. Yale University Manuscript.

Deaton, Angus, "Theoretical and Empirical Approaches to Consumer Demand Under Rationing," 1981. In Essays in the Theory and Measurement of Consumer Behaviour: In Honour of Sir Richard Stone, edited by Angus Deaton. Cambridge University Press.

Doherty, Jim P., Edward C. Norton, and James E. Veney, "China's One-Child Policy: The Economic Choices and Consequences Faced by Pregnant Women," Social Science and Medicine, 2001, 52, 745-761. 
Fernandez, Raquel, Nezih Guner, and John Knowles, "Love and Money: A Theoretical and Empirical Analysis of Household Sorting and Inequality," The Quarterly Journal of Economics, 2005, 120 (1), 273-344.

Galichon, Alfred and Bernard Selanie, "Matching with Trade-offs: Revealed Preferences over Competing Characteristics," 2009. Ecole Polytechnique Manuscript.

Iyigun, Murat and Randall P. Walsh, "Building the Family Nest: Premarital Investments, Marriage Markets, and Spousal Allocations," Review of Economic Studies, 2007, 74 (2), 507-535.

Knuth, Donald, Marriages Stables, Montreal: Les Presses de l'Universite de Montreal, 1976.

Legros, Patrick and Andrew F. Newman, "Monotone Matching in Perfect and Imperfect Worlds," Review of Economic Studies, 2002, 69 (4), 925-942.

and _ , "Beauty is a Beast, Frog is a Prince: Assortative Matching with Nontransferabilities," Econometrica, 2007, 75 (4), 1073-1102.

Lise, Jeremy, Costas Meghir, and Jean-Marc Robin, "Matching, Sorting and Wages," 2008. University College of London Manuscript.

Liu, Haoming and Jinfeng Lu, "Measuring the Degree of Assortative Mating," Economic Letters, 2006, 92 (3), 317-322.

Lundberg, Shelly and Robert A. Pollak, "Efficiency in Marriage," Review of Economics of the Household, 2003, 1, 153-167.

Maasoumi, Esfandiar, "On Mobility," 1996. In Handbook of Applied Economic Statistics, edited by D. Giles and A. Ullah. Marcel Dekker.

Mendes, Rute, Gerard J. Van Den Berg, and Maarten Lindeboom, "An Empirical Assessment of Assortative Matching in the Labor Market," 2007. IZA Discussion Paper No. 3053.

Neary, Peter and Kevin Roberts, "The Theory of Household Behaviour Under Rationing," European Economic Review, 1980, 13, 25-42. 
Peng, Xizhe and Zhigang Guo, The Changing Population of China 2000. Blackwell Publishing.

Peters, Michael and Aloysius Siow, "Competing Pre-Marital Investments," Journal of Political Economy, 2002, 110, 592-608.

Quah, Danny, "Empirics for Economic Growth and Convergence," European Economic Review, 1996, 40, 1353-1375.

Rao, C. Radhakrishna, Linear Statistical Inference and Its Applications 1973. John Wiley \& Sons.

Roth, Alvin E. and Marilda A. Oliveira Sotomayor, Two-Sided Matching: A Study in Game-Theoretic Modelling and Analysis Econometric Society Monographs No. 18, Cambridge: Cambridge University Press, 1990.

Shaked, Moshe and George J. Shanthikumar, Stochastic orders, Springer, 2007.

Shimer, Robert and Lones Smith, "Assortative Matching and Search," Econometrica, 2000, 68 (2), 343-369.

Shorrocks, Anthony, "Income Mobility and the Markov Assumption," Economic Journal, 1976, 86, 566-577.

__ , "The Measurement of Mobility," Econometrica, 1978, 46, 1013-1024.

Siow, Aloysius, "Testing Becker's Theory of Positive Assortative Matching," 2009. University of Toronto Working Paper 356.

Suen, Wing and Hon-Kwong Lui, "A Direct Test of the Efficient Marriage Market Hypothesis," Economic Inquiry, 1999, 37 (1), 29-46.

Therborn, Goran, Between Sex and Power: Family in the World 1900-2000 2004. Routledge.

Wong, Linda, "Structural Estimation of Marriage Models," Journal of Labor Economics, 2003, 27 (3), 699-728.

Zhang, Weiguo, Economic Reforms and Fertility Behaviour: A Study of a North China Village 2002. Routledge Curzon. 


\section{A Appendix}

\section{A.1 Proof of Propositions}

Proof. Proof of Proposition 1: Let $k^{\prime}$ be the optimal level of investment per child with $\widetilde{n}$ children in the family. Differentiating $k^{\prime}$ with respect to $\widetilde{n}$ from (7),

$$
\frac{\partial k^{\prime}}{\partial \widetilde{n}}=\frac{q_{n} \tilde{n}+q+q_{n} k^{\prime}-q_{k n}\left(y x-\widetilde{n} k^{\prime}\right)}{q_{k k}\left(y x-\widetilde{n} k^{\prime}-q_{k} \widetilde{n}-q_{n} \widetilde{n}\right)} \leq 0
$$

Given assumption 1, a binding constraint on the number of children, i.e. one that is lower than what the parents would have chosen, would increase investments in children.

Proof. Proof of Proposition 2: Differentiating (6) and (7) with respect to $y$ respectively gives,

$$
\begin{aligned}
\frac{\partial n^{*}}{\partial y} & =-\frac{q_{n} x}{\left(q_{n n}\left(y x-n^{*} k^{*}\right)-2 q_{n} k^{*}\right)} \geq 0 \\
\frac{\partial k^{*}}{\partial y} & =-\frac{q_{k} x}{\left(q_{k k}\left(y x-n^{*} k^{*}\right)-2 q_{k} k^{*}\right)} \geq 0
\end{aligned}
$$

Therefore, an increase in income would increase the number of children in the family, and the level of investment per child.

Proof. Proof of Proposition 3: For the proof of point 1, differentiating $\underline{t_{w}^{R}}$ in $\sqrt{10}$ with respect to the number of children $\widetilde{n}$,

$$
\frac{\partial t_{w}^{R}}{\partial \widetilde{n}}=\frac{q k^{\prime}-q_{\widetilde{n}}\left(y x-\widetilde{n} k^{\prime}\right)}{q_{\underline{t_{w}^{R}}}\left(y x-\widetilde{n} k^{\prime}\right)+q y x_{\underline{t_{w}^{R}}}-y v_{\underline{t_{w}^{R}}}} \leq 0
$$

Where $k^{\prime}$ is the optimal choice of $k$ given $t_{w}=\underline{t_{w}^{R}}, t_{h}$ and $\tilde{n}$. Since $\tilde{n}$ is binding from below, by revealed preference the marginal benefit would be greater than the marginal cost, and the numerator is non-positive. By assumption 3, and $\underline{t_{w}^{R}} \leq t_{h}$, the greater the type of an individual, the greater the gains to marriage, so the denominator is positive.

For the upper bound on the reservation value, we differentiate $\overline{t_{w}^{R}}$ in 11 with respect to $\widetilde{n}$ as above.

$$
\frac{\partial \overline{t_{w}^{R}}}{\partial \widetilde{n}}=\frac{q k^{\prime \prime}-q_{\widetilde{n}}\left(y x-\widetilde{n} k^{\prime \prime}\right)}{q_{t_{w}^{R}}\left(y x-\widetilde{n} k^{\prime \prime}\right)+q y x_{\overline{t_{w}^{R}}}-y v_{\overline{t_{w}^{R}}}} \geq 0
$$

Where $k^{\prime \prime}$ is the optimal choice of $k$ given $t_{w}=\overline{t_{w}^{R}}, t_{h}$ and $\widetilde{n}$. The numerator as before is non-positive. By assumption 3 , and $\overline{t_{w}^{R}} \geq t_{h}$, the denominator is negative, and point 1 follows. 
Since there is a narrowing in the range of potential matches around the agents type, incidences of assortative matches rise. Formally, let a man of type $t_{h}$ be matched with and married to a woman of type $t_{w}^{*}$. Then

$$
\operatorname{Pr}\left(\underline{t_{w}^{R}} \leq t_{w}^{*} \leq \overline{t_{w}^{R}}\right)=1
$$

It follows that,

$$
\int_{\underline{t_{w}^{R}}}^{\overline{t_{w}^{R}}} f\left(t_{w}^{*} \mid t_{h}\right) d t_{w}^{*}=\frac{1}{f\left(t_{h}\right)} \int_{\underline{t_{w}^{R}}}^{\overline{t_{w}^{R}}} g\left(t_{w}^{*}, t_{h}\right) d t_{w}^{*}=\frac{1}{f\left(t_{h}\right)}\left[G\left(\overline{t_{w}^{R}}, t_{h}\right)-G\left(\underline{t_{w}^{R}}, t_{h}\right)\right]=1
$$

where $g($.$) and G($.$) are respectively the joint density and joint distribution functions.$ The total differential of (A-7) with respect to $\widetilde{n}$ may be written as,

$$
\frac{1}{f\left(t_{h}\right)}\left[\frac{\partial G\left(\overline{t_{w}^{R}}, t_{h}\right)}{\partial \overline{t_{w}^{R}}} \frac{\partial \overline{t_{w}^{R}}}{\partial \widetilde{n}}-\frac{\partial G\left(\underline{t_{w}^{R}}, t_{h}\right)}{\partial \underline{t_{w}^{R}}} \frac{\partial t_{w}^{R}}{\partial \widetilde{n}}\right] d \widetilde{n}+\frac{1}{f\left(t_{h}\right)} \frac{\partial\left[G\left(\overline{t_{w}^{R}}, t_{h}\right)-G\left(\underline{t_{w}^{R}}, t_{h}\right)\right]}{\partial \widetilde{n}} d \widetilde{n}=0
$$

Since

$$
\frac{1}{f\left(t_{h}\right)}>0, \frac{\partial G\left(t_{w}, t_{h}\right)}{\partial t_{w}}>0, \frac{\partial \overline{t_{w}^{R}}}{\partial \widetilde{n}}>0, \frac{\partial t_{w}^{R}}{\partial \widetilde{n}}<0
$$

It may be observed that

$$
\frac{\partial\left[G\left(\overline{t_{w}^{R}}, t_{h}\right)-G\left(\underline{t_{w}^{R}}, t_{h}\right)\right]}{\partial \widetilde{n}}<0
$$

Proof. Proof of Proposition 4: As in the proof of proposition 3, differentiate $\underline{t_{w}^{R}}$ and $\overline{t_{w}^{R}}$ in (10) and (11) with respect to $y$ respectively.

$$
\frac{\partial t_{w}^{R}}{\partial y}=\frac{-q x+v\left(\underline{t_{w}^{R}}\right)+v\left(t_{h}\right)}{q_{\underline{t_{w}^{R}}}(y x-\underline{n k})+q y x_{\underline{t_{w}^{R}}}-y v_{\underline{t_{w}}}} \leq 0
$$

First note that by assumption 3 , and $\underline{t_{w}^{R}} \leq t_{h}$, the greater the type of an individual, the greater the gains to marriage, so the denominator is positive. Secondly, by assumption 5, the numerator is negative, and the inequality follows.

$$
\frac{\partial \overline{t_{w}^{R}}}{\partial y}=\frac{-q x+v\left(\overline{t_{w}^{R}}\right)+v\left(t_{h}\right)}{q_{\overline{t_{w}^{R}}}(y x-\bar{n} \bar{k})+q y x_{t_{w}^{R}}-y v_{t_{w}^{R}}} \geq 0
$$

By assumption 3, and $\overline{t_{w}^{R}} \geq t_{h}$, the denominator is negative. By assumption 5, the numerator is negative, and the inequality follows. The rest of the arguments are similar to proposition 3. 


\section{A.2 A Brief Discussion about the Overlap Measure}

To see that the Overlap Index is asymptotically normally distributed, define

$$
\mathbf{V}=\sqrt{n}\left[\begin{array}{cccc}
\frac{j_{1,1}-\pi_{1,1}}{\sqrt{\pi_{1,1}}} & \frac{j_{1,2}-\pi_{1,2}}{\sqrt{\pi_{1,2}}} & \ldots & \frac{j_{1, N}-\pi_{1, N}}{\sqrt{\pi_{1, N}}} \\
\frac{j_{2,1}-\pi_{2,1}}{\sqrt{\pi_{2,1}}} & \frac{j_{2,2}-\pi_{2,2}}{\sqrt{\pi_{2,2}}} & \ldots & \frac{j_{2, N}-\pi_{2, N}}{\sqrt{\pi_{2, N}}} \\
: & : & \ldots & : \\
\frac{j_{M, 1}-\pi_{M, 1}}{\sqrt{\pi_{M, 1}}} & \frac{j_{M, 2}-\pi_{M, 2}}{\sqrt{\pi_{M, 2}}} & \ldots & \frac{j_{M, N}-\pi_{M, N}}{\sqrt{\pi_{M, N}}}
\end{array}\right]
$$

where $\pi_{m, n}, m \in\{1,2, \ldots, M\}$ and $n \in\{1,2, \ldots, N\}$, is the true probability of event $\{m, n\}$ occurring, and is the typical element of $\Pi$. Then denote $\mathbb{V}=\operatorname{vec} \mathbf{V}$. Next define

$$
\mathbb{v}^{\prime}=\left(\sqrt{\pi_{1,1}}, \ldots, \sqrt{\pi_{1, N}}, \ldots, \sqrt{\pi_{M, 1}}, \ldots, \sqrt{\pi_{M, N}}\right)
$$

and

$$
\Omega=\mathbf{I}-\mathbb{v} \mathbb{V}^{\prime}
$$

Then by the results in Rao (1973) pages 383 and 391, and Anderson et al. (2010), we have

$$
\mathbb{V} \stackrel{a}{\rightarrow} N_{M N}(\mathbf{0}, \Omega)
$$

Define the matrix of estimated probabilities as $\mathbf{J}$, and let $\mathbf{j}=\operatorname{vec} \mathbf{J}$ and $\pi=\operatorname{vec} \boldsymbol{\Pi}$ where vec is the vec-operator. Then,

$$
\begin{array}{r}
\mathbf{j} \stackrel{a}{\rightarrow} N_{M N}\left(\pi, \frac{1}{n}(\operatorname{dg}(\mathbb{v})) \Omega(\operatorname{dg}(\mathbb{v}))^{\prime}\right) \\
\Rightarrow \mathbf{i}^{\prime} \mathbf{j} \stackrel{\stackrel{a}{\rightarrow}}{\rightarrow} N\left(\mathbf{i}^{\prime} \pi, \frac{1}{n} \mathbf{i}^{\prime}(\operatorname{dg}(\mathbb{v})) \Omega(\operatorname{dg}(\mathbb{v}))^{\prime} \mathbf{i}\right)
\end{array}
$$

where $\mathbf{i}$ is a vector of ones. Let $\mathbf{j}^{p}$ and $\mathbf{j}^{e}$ be the vectorized joint density under positive assortative matching and the empirical counterpart respectively. Define $\mathbf{j}^{\min }=\min \left\{\mathbf{j}^{p}, \mathbf{j}^{e}\right\}$. Likewise, let $\pi^{p}$ and $\pi^{e}$ be the corresponding vectorized true probabilities (from vec $\Pi^{p}$ and $\operatorname{vec} \Pi^{e}$ respectively), and let $\pi^{\min }=\min \left\{\pi^{p}, \pi^{e}\right\}$. Then the Overlap Index is $\mathbf{O} \mathbf{V}_{p}=\mathbf{i}^{\prime} \mathbf{j}^{\min }$. It is clear then asymptotically by equation (A-18),

$$
\mathbf{O V}_{p}:=\mathbf{i}^{\prime} \mathbf{j}^{\min } \stackrel{a}{\rightarrow} N\left(\mathbf{i}^{\prime} \pi^{\min }, \frac{1}{n^{\min }} \mathbf{i}^{\prime}\left(\operatorname{dg}\left(\mathbb{v}^{\min }\right)\right) \Omega^{\min }\left(\operatorname{dg}\left(\mathbb{v}^{\min }\right)\right)^{\prime} \mathbf{i}\right)
$$

where $\Omega^{\min }=\mathbf{I}-\mathbb{V}^{\min _{\mathbb{V}}}{ }^{\min \prime}$ and

$$
\mathbb{V}^{\min \prime}=\left(\sqrt{\pi_{1,1}^{\min \prime}}, \ldots, \sqrt{\pi_{1, N}^{\min \prime}}, \sqrt{\pi_{2,1}^{\min \prime}}, \ldots, \sqrt{\pi_{2, N}^{\min \prime}}, \sqrt{\pi_{3,1}^{\min \prime}}, \ldots, \sqrt{\pi_{M, N}^{\min \prime}}\right)
$$

Note that the variance-covariance matrix can be estimated by replacing $\mathbb{v}^{\text {min }}$ with $\mathbf{j}^{\min }$. 